\title{
Coqueluche grave: Estado del arte
}

\author{
Alejandro Donoso, Daniela Arriagada, Pablo Cruces y Franco Díaz
}

\begin{abstract}
Hospital Padre Hurtado Santiago, Chile. Unidad de Gestión Clínica de Niño Área de Cuidados Críticos $(A D, P C, F D)$

Facultad de Medicina Clínica Alemana-Universidad del

Desarrollo, Santiago, Chile. Programa de Medicina Intensiva en Pediatría (AD, DA)

Sin financiamiento externo Sin conflictos de interés.

Recibido: 12 de enero de 2012 Aceptado: 2 de abril de 2012

Correspondencia a: Alejandro Donoso Fuentes adonoso@hurtadohosp.cl
\end{abstract}

\section{Introducción}

L a coqueluche (tos ferina) es una enfermedad infecciosa, altamente contagiosa, cuyo agente etiológico es Bordetella pertussis, un cocobacilo gramnegativo de reservorio humano exclusivo, de transmisión respiratoria ${ }^{1}$.

En Chile la infección por B. pertussis es un problema de salud pública, siendo una enfermedad de notificación obligatoria, definida por el Ministerio de Salud (MINSAL) como "cuadro, habitualmente de comienzo insidioso, con síntomas similares a un resfrío y caracterizado por coriza, tos leve no productiva y fiebre moderada, que dura 1 a 2 semanas, para luego presentar tos severa caracterizada por paroxismos (accesos repetidos y tos violenta) los que pueden ser seguidos de estridor inspiratorio y en ocasiones, de vómito. El cuadro clínico se manifiesta con mayor gravedad en los lactantes y en particular bajo 3 a 6 meses de edad, en quienes la infección cursa frecuentemente con apneas repetidas"2.

En la mayoría de los países, la vigilancia de la coqueluche se basa en notificaciones clínicas e informes de laboratorio. Desde la década pasada se ha observado un aumento significativo de los casos, incluso en países desarrollados con buenas coberturas de vacunación ${ }^{3}$. No obstante, comparar la incidencia de esta enfermedad entre los distintos países es difícil, ya que depende de las diferencias entre la definición de caso, acceso a pruebas diagnósticas, experiencia médica para identificar su cuadro clínico y si la enfermedad es de declaración obligatoria según la normativa de salud pública de cada país.

En ocasiones su forma de presentación varía, especialmente en pacientes bajo seis meses de edad o sin una inmunización completa ${ }^{4-8}$. En estos pacientes se puede desarrollar una coqueluche grave (CG), definida como falla respiratoria, hipoxemia refractaria e hipertensión pulmonar (HTP), la cual presenta una elevada tasa de morbi-mortalidad asociada.

El objetivo de la presente comunicación es una revisión del estado del arte en coqueluche grave.

\section{Epidemiología mundial}

En la era prevacunación, la coqueluche era considerada una enfermedad endémica con picos epidémicos cada 2 a 5 años, siendo una enfermedad obligada de la infancia y esporádica en adultos y senescentes ${ }^{9}$. La introducción de la vacuna DPT en la década del cuarenta fue efectiva y, para los años setenta la tasa de reporte de la infección disminuyó cerca de 150 veces y se mantuvo entre 0,5 1 caso por 100.000 habitantes ${ }^{10}$. Sin embargo, en los últimos veinte años hubo un desplazamiento en la edad de los casos susceptibles, reportándose un aumento en adolescentes y adultos jóvenes, siendo este el factor más importante para el resurgimiento de la coqueluche y a su vez el que contribuye significativamente al incremento de casos en lactantes bajo un año de edad $d^{7,11-15}$.

Según datos de la Organización Mundial de la Salud (OMS), la enfermedad producida por $B$. pertussis ocupa el quinto puesto entre las causas de muerte prevenibles por vacuna ${ }^{16}$. A pesar de la amplia inmunización se estima que cada año se presentan entre 20 y 50 millones de casos en el mundo con aproximadamente 200.000 a 400.000 muertes anuales, de las cuales $90 \%$ ocurre en países en desarrollo, la mayoría en lactantes no vacunados o con vacunación incompleta ${ }^{4,10,17}$.

Informes de los Centros para el Control y Prevención de Enfermedades de Atlanta (Centers for Disease Control and Prevention, $C D C$ ), en Estados Unidos de América (E.U.A.) señalan que se registró el triple de casos en el año 2005 con respecto al año $2001^{18}$, hecho que se ha 
evidenciado también en otras partes del mundo. En Latinoamérica, hay escasas publicaciones sobre este problema de salud pública, a pesar que contribuye aproximadamente al $90 \%$ de las hospitalizaciones, complicaciones y muertes atribuidas a esta enfermedad en el mundo en desarrollo ${ }^{19}$. Según estimaciones de la OMS, la región de las Américas fue responsable de aproximadamente $7 \%$ de los casos de coqueluche en el mundo durante el año $2005^{20}$. Excluyendo Canadá y E.U.A., un total de 6.936 casos fueron notificados en el año 2006, cuya distribución en orden decreciente fue la siguiente: Argentina (1.607), Chile (1.285), Venezuela (1.183), Costa Rica (1.037), Brasil (797), Colombia (233), México (171), Nicaragua (148), Honduras (138) y Panamá (132), entre otros ${ }^{21}$.

La coqueluche es una realidad en Latinoamérica, causando gran morbi-mortalidad en la población más vulnerable. Se requiere una alta sospecha clínica e identificar en forma precoz los casos con el fin de iniciar un tratamiento y seguimiento oportuno.

Es necesario continuar desarrollando estudios que evalúen el real impacto de esta enfermedad y así poder establecer una serie de estrategias destinadas a la prevención y mejoría de sistema de vigilancia epidemiológica como también en los métodos diagnósticos de ésta.

\section{Epidemiología en Chile}

Como señala Laval, no existen relatos de epidemias importantes de coqueluche en el país entre los siglos XVI y XVIII, con poca información disponible sobre las sucedidas en el siglo XIX (La Serena en 1851, Valdivia en $1853)^{22}$. A fines del siglo XIX, el doctor Carlos Sommers registra que entre los años 1892 y 1895 fallecieron por coqueluche 8.181 enfermos, lo que pudo deberse a la gravedad de las epidemias que ocurrieron a partir de $1890^{23,24}$.

Actualmente, a pesar de la introducción de la vacuna anti-pertussis (DP) en el programa nacional de inmunizaciones en el año 1961, y en 1974 como DPT, ésta sigue siendo una enfermedad vigente, siendo potencialmente grave en pacientes bajo seis meses de edad.

En el año 1995 la tasa de incidencia de coqueluche era de 2,5 por cien mil habitantes, cifra que se triplicó el año siguiente, llegando a una tasa máxima en el año 2000 de 23,4 por cien mil habitantes. En la última década se observó una disminución progresiva de las tasas de coqueluche hasta llegar a una de 4,0 por cien mil habitantes ${ }^{25}$.

No obstante, durante el último trimestre del año 2010 se constató un aumento de las notificaciones, asociado a un aumento de casos aislados y a brotes intrafamiliares e institucionales. Durante el año 2011, la tasa de incidencia acumulada de coqueluche correspondió a 12,6 por cien mil habitantes (2.167 casos), cifra que triplica la cifra del año 2010 durante este mismo período ${ }^{26}$.
La distribución de casos por grupo etario es un hecho a destacar ya que $51 \%$ corresponden a lactantes bajo un año de edad y de éstos, $33 \%$ son pacientes con edad igual o menor de un mes. La tasa de incidencia en lactantes bajo un año es de 441,7 por 100.000 niños en comparación con el grupo de 1-4 años que presenta una tasa de incidencia de 41,4 por 100.000 niños ${ }^{26}$. Otro hecho a enfatizar es que de las notificaciones en lactantes bajo un año de edad, $80 \%$ de los casos no presenta inmunización completa (bajo 6 meses).

Históricamente la mortalidad anual es de 6 a 9 lactantes bajo un año de edad ${ }^{25}$; sin embargo, a la fecha (diciembre de 2011) se han registrado 13 fallecimientos, siendo la totalidad de ellos lactantes bajo 6 meses de edad ${ }^{26}$.

\section{Mecanismo de patogenicidad}

Actualmente, gracias al avance en biología molecular, se ha podido caracterizar, aunque en forma incompleta, los componentes patogénicos de la bacteria ${ }^{27-29}$. Sin embargo, hay que considerar que estos mecanismos han sido estudiados y fundamentados en modelos animales, extrapolándose sus efectos a humanos.

Desde el punto de vista biomolecular, B. pertussis comparte con las otras especies de bordetela patógenas para el humano, un sistema prácticamente idéntico de control de virulencia, codificada en su genoma, en el locus $b v g A S$. Este sistema de transducción de señales, denominado $B v g A S$, está compuesto por dos partes $B v g A$ y $B v g S^{30-32}$. BvgS es un "sensor" transmembrana, compuesto por cuatro segmentos ${ }^{33}$, el cual se auto-fosforila y modula la activación del $B v g A$, regulador de respuesta de unión a $\mathrm{ADN}^{34}$

A través de este sistema se controlan, al menos, tres fases fenotípicas de B. pertussis en respuesta a los cambios ambientales (temperatura del cultivo, déficit de ciertos nutrientes, etc.) y que permite regular la expresión de sus factores de virulencia ${ }^{35}$. Lacey ${ }^{36}$ describió estos modos o fases de la bacteria: X, I y C, según su capacidad de producir enfermedad en modelos animales, siendo X la relacionada con mayor patogenicidad ${ }^{27,28}$. Básicamente, en la fase $\mathrm{X} \mathrm{o} \mathrm{Bvg}^{+}$, la expresión de factores de adhesión y toxinas son indispensables para la colonización e infección de las células hospedera, mientras que en la fase C o Bvg-, su expresión se inhibe y la expresión de otras proteínas se activa. El rol de estos factores, en la fase $\mathrm{C}$ o Bvg-, es desconocido. Se ha sugerido que ellos pueden ser necesarios para evadir la respuesta inmune basado en la sobrevida intracelular de B. pertussis ${ }^{37}$. Finalmente, estos factores podrían contribuir a la transmisión del microorganismo.

Se ha descrito la coqueluche como una "toxemia", haciendo referencia a que la bacteria produce un gran 
daño en el epitelio respiratorio, pero sin invasión a la submucosa como tampoco paso al torrente sanguíneo. Una serie de proteínas estructurales como de secreción están implicadas, las cuales están listadas, junto a su función principal, en la Tabla 1. Un evento crucial en el inicio de la infección es la adhesión y anclaje de la bacteria al epitelio respiratorio, especialmente a las células ciliadas. Al menos siete proteínas bien caracterizadas participan facilitando este proceso, siendo las más importantes fimbria (FIM), toxina pertussis (TP), hemaglutinina filamentosa (HFA) y pertactina $(\mathrm{PRN})^{27-29,38-40}$. Es importante destacar la redundancia funcional de estas proteínas que permite la pérdida de función o la ausencia de una de ellas sin alterar significativamente la adhesión y anclaje al epitelio, siendo esto una razón hipotética propuesta para explicar que la inmunización activa no sea suficiente para prevenir la colonización $^{27,28,39}$.

Otro aspecto relevante es la evasión de la respuesta inmune, facilitada especialmente por la toxina adenilatociclasa (CyaA), la que es activada por la calmodulina de las células hospederas. Esta toxina ingresa a los neutrófilos, aumentando en forma excesiva la producción de AMP cíclico (cAMP), inhibiendo la fagocitosis y la actividad de las células natural killer $27,28,41$.

La destrucción de las células ciliadas del epitelio respiratorio se debe principalmente a la acción de la citotoxina traqueal (CTT) y en menor grado por CyaA. Los efectos citopáticos son específicos sobre las células ciliadas, produciendo disrupción de tight junctions, edema mitocondrial y extrusión de las células ciliadas ${ }^{1,27-29}$. Apoyados en modelos experimentales animales, se postula que esta gran destrucción epitelial se produce mediante un aumento de la producción de interleuquina $1-\alpha$, estimulada directamente por la CTT en células no ciliadas productoras de mucus, que estimularía la expresión de óxido nítrico sintetasa (NOS) $)^{1,27-29}$. El óxido nítrico (NO) difundiría hacia las células vecinas en grandes cantidades, siendo las células ciliadas susceptibles en un mayor grado al daño por éste ${ }^{42}$.

La principal toxina producida por B. pertussis es la TP, también denominada pertusinógeno. Esta es una proteína de secreción con actividad ribosiladora de ADP, compuesta por dos subunidades: A que es enzimáticamente activa y $\mathrm{B}$, una estructura con forma anular que se une a la membrana de las células eucariontes y facilita el ingreso de la unidad $\mathrm{A}^{1,27}$. Una vez en el citosol, escindiéndose de la subunidad B, la subunidad A cataliza la transferencia de NAD (nicotidamida adenina dinucleótido) a la subunidad alpha del sistema de transducción de señales llamado proteína $\mathrm{G}^{27,28}$. Los efectos biológicos que se atribuyen a la alteración de estas vías de transducción de señales son diversos. Está bien establecido en modelos animales que la TP es la causa de las alteraciones sistémicas asociado a la infección por B. pertussis, tales como leucocitosis, hipoglicemia (hiperinsulinemia) y sensibilización a histamina ${ }^{43}$. Asimismo la TP juega un rol importante en la promoción de infección en las vías respiratorias por la supresión y modulación de la respuesta inmune e inflamatoria del hospedero ${ }^{44}$. Se ha descrito que la TP retrasa el reclutamiento temprano de neutrófilos y su influjo a la vía aérea por inhibición de la up regulation de los genes que expresan citoquinas $(K C, M I P-2 \text { y } L I X)^{45}$, inhibe la producción de anticuerpos séricos y a su vez reduce la capacidad de éstos para controlar la infección ${ }^{46,47}$ y suprime la respuesta inmune adaptativa por efecto sobre diferentes células (monocitos, células dendríticas) ${ }^{48,49}$.

Otros de los efectos de esta toxina es el bloqueo de los receptores $\alpha$-2 adrenérgicos y los receptores dopaminérgicos (D2), responsable en parte de la resistencia a catecolaminas observada en los casos graves ${ }^{50,51}$.

La TP, como ya se mencionó, es responsable in vitro de la leucocitosis, incrementando el recuento periférico de neutrófilos y linfocitos, siendo el segundo mucho más marcado. Esto no se debe a un aumento de su producción, sino a una mayor migración desde sitios extravasculares, acrecentando su número absoluto en circulación al estar también disminuida la quimiotaxis y migración ${ }^{1,52}$.

Existen divergencias antigénicas entre las cepas utilizadas en vacunas y las aisladas en clínica en relación a las proteínas de superficie que confieren inmunidad protectora: TP, PRN y FIM ${ }^{53-56}$. Recientemente, se encontró evidencia que polimorfismo en el promotor de la $\mathrm{TP}(p t x P)$ puede ser importante para la adaptación de este patógeno ${ }^{57} \mathrm{y}$ así ser un factor más del resurgimiento de esta enfermedad. En los últimos veinte años, dos alelos del ptxP, ptxP1 y ptxP3 han predominado en estudios efectuados en diversas latitudes, principalmente en Europa. Las cepas con $p t x P 3$ producen más TP y, según datos epidemiológicos, estas cepas tendrían mayor virulencia. Esto tendría implicancia en la inmunidad generada por las vacunas, ya que las cepas utilizadas en ésta serían diferentes a las aisladas en la población, por lo tanto, la inmunidad adquirida por vacuna no sería protectora. Empero, este fenómeno no puede extrapolarse a nivel mundial, ya los resultados de estas investigaciones han sido variables.

\section{Cuadro clínico}

Existen varios factores descritos que modifican las manifestaciones clínicas de la infección por B. pertussis, entre ellas la edad del paciente, el estado de vacunación y el antecedente de infección previa ${ }^{58,59}$.

La coqueluche clásica, su clínica y diagnóstico, han sido revisado en forma exhaustiva en otras publicaciones $^{38,60,61}$. En neonatos y lactantes con vacunación incompleta (menos de tres dosis), puede ser particularmente grave con una elevada tasa de complicaciones y mortalidad aproximada al $1 \%{ }^{62-64}$. 


\section{Infectología al Día}

\begin{tabular}{|c|c|c|c|c|}
\hline Factor & Regulación BvgAS & Molécula & Función principal & Otras funciones \\
\hline Toxina pertussis & Sí; fase $(+)$ & $\begin{array}{l}\text { Protómero A y múltiples } \\
\text { subunidades B }\end{array}$ & Toxina y factor de adhesión & Causa leucocitosis y linfocitosis \\
\hline Hemaglutininas & Sí; fase (+) & Proteína filamentosa, 220 kDa & $\begin{array}{l}\text { Factor de adhesión; predomina en } \\
\text { la traquea }\end{array}$ & Desconocida \\
\hline Fimbria 2 y 3 & Sí; fase (+) & $\begin{array}{l}\text { Proteínas pequeñas, filamentosas } \\
(23 \mathrm{kDa})\end{array}$ & $\begin{array}{l}\text { Factor de adhesión; predomina en } \\
\text { la traquea }\end{array}$ & $\begin{array}{l}\text { Aglutinógenos; mantiene la } \\
\text { infección }\end{array}$ \\
\hline Pertactina & Sí; fase $(+)$ & $\begin{array}{l}\text { Proteína de membrana externa } \\
\text { (69 kDa) }\end{array}$ & Factor de adhesión & $\begin{array}{l}\text { Antígeno protector (modelo en } \\
\text { ratón) }\end{array}$ \\
\hline Adenilato ciclasa & Sí; fase $(+)$ & Toxina & $\begin{array}{l}\text { Toxina; inhibe la fagocitosis por } \\
\text { aumento de AMPC }\end{array}$ & $\begin{array}{l}\text { Inhibe la quimiotaxis e induce } \\
\text { apoptosis de los macrófagos }\end{array}$ \\
\hline Citotoxina traqueal & No & Derivado de peptidoglicano & $\begin{array}{l}\text { Toxina; paraliza el sistema mu- } \\
\text { cociliar }\end{array}$ & $\begin{array}{l}\text { Inhibe la síntesis de ADN y muerte } \\
\text { celular }\end{array}$ \\
\hline Toxina dermonecrótica & Sí; fase $(+)$ & Toxina termolábil (140 kDa) & $\begin{array}{l}\text { Toxina; necrosis cutánea y vaso- } \\
\text { constricción }\end{array}$ & $\begin{array}{l}\text { Efecto sólo después de inyección } \\
\text { en la piel }\end{array}$ \\
\hline Factor de colonización traqueal & Sí; fase $(+)$ & Proteína rica en prolina & $\begin{array}{l}\text { Factor de adhesión; predomina en } \\
\text { la traquea }\end{array}$ & Desconocida \\
\hline Factor de resistencia al complemento & Sí; fase $(+)$ & Proteína de membrana externa & Factor de adhesión & Provee resistencia al complemento \\
\hline Virulencia activada del gen 8 (vag 8) & Sí; fase $(+)$ & Proteína de membrana externa & Factor de adhesión? & Desconocida \\
\hline Sistema de secreción tipo III & Sí; fase $(+)$ & $\begin{array}{l}\text { Varias proteínas aún no especi- } \\
\text { ficadas }\end{array}$ & $\begin{array}{l}\text { Secreta proteínas efectoras en } \\
\text { células hospederas }\end{array}$ & Desconocida \\
\hline
\end{tabular}

La complicación más frecuente es la neumonía (6$15 \%$ de los casos), la cual asociada a falla respiratoria, hiperleucocitosis e HTP conforman el cuadro clínico de $\mathrm{CG}^{65-67}$, el cual conlleva una mortalidad en $\sim 75 \%$ de los casos, a pesar de las medidas terapéuticas empleadas.

Hace 25 años se iniciaron los reportes de casos fatales de coqueluche en lactantes pequeños, asociados a altos recuentos leucocitarios, que evolucionan a falla respiratoria y colapso cardiopulmonar ${ }^{40,68,69}$. En 1993 Goulin y cols. ${ }^{70}$, por primera vez lograron demostrar la presencia de HTP mediante monitoreo hemodinámico invasor en tres lactantes, confirmando de esta forma el ser un evento fisiopatológico crucial en el desarrollo de la CG.

La mayoría de los casos fatales de coqueluche ocurren en pacientes bajo un año de edad, y $90 \%$ se produce bajo seis meses de edad, siendo ésta la gran población en riesgo para desarrollar CG. Debido a la edad de los pacientes que desarrollan CG, los síntomas característicos de esta enfermedad pueden estar ausentes, siendo la principal razón para el sub-diagnóstico de esta patología ${ }^{7,68,69,71,72}$.

Se han descrito varios factores de riesgo de mortalidad, los cuales incluyen: tener menos de un año de edad, vacunación ausente o incompleta, neumonía y convulsiones $^{67,71,73,74}$. La hiperleucocitosis es otro factor de riesgo, siendo descrito por Pierce y cols. ${ }^{75}$, que un valor mayor a $100.000 / \mathrm{mm}^{3}$ es un factor independiente para resultado fatal. Mikelova y cols. ${ }^{71}$, diseñaron un modelo multivariable para predecir la evolución letal, resultando sólo la presencia de neumonía e hiperleucocitosis asociadas en forma significativa. No encontraron un valor absoluto del recuento leucocitario que lograra predecir una evolución letal. No obstante, la gran mayoría de los casos reportados con resultado ominoso cursaron con cifras muy elevadas de leucocitos durante su evolución ${ }^{66,76,77}$.

En nuestra experiencia, un signo clínico de gran importancia, muchas veces subvalorado, es la presencia de taquicardia sinusal inexplicada, un evento común que debiera ser considerado como un signo precoz de alarma $^{7,78,79}$.

La fisiopatología que explica la evolución grave no ha sido posible dilucidar en su totalidad. Cabe resaltar lo estereotipado de la evolución de estos pacientes: hipoxemia grave refractaria a tratamiento, HTP que lleva a colapso cardio-circulatorio, la que finalmente no responde a terapia, ocasionando un desenlace fatal.

\section{Fisiopatología}

Se ha sugerido que la neumonía por $B$. pertussis puede gatillar una cascada de eventos que incluyen hipoxia, acidosis, vasoconstricción pulmonar e incremento de la masa leucocitaria, los que condicionarían una reducción del flujo sanguíneo pulmonar. Estos efectos producirían una marcada elevación de la presión de los vasos sanguíneos pulmonares exacerbando la hipoxemia, causando finalmente falla cardíaca, shock y síndrome de distress respiratorio agudo. Esta condición agravaría la vasocons- 
tricción hipóxica generando un círculo vicioso de HTP refractaria ${ }^{80}$, lo que en casos graves puede desencadenar disfunción ventricular derecha y finalmente la muerte.

Modelos teóricos atribuyen un rol protagónico a la $\mathrm{TP}^{81-83}$, la que produce un desbalance en el tono de la vasculatura pulmonar al inhibir una serie de agentes vasodilatadoras del endotelio, disminuyendo la síntesis de óxido nítrico, y en consecuencia favoreciendo la actividad de vasoconstrictores locales como la endotelina- ${ }^{84}$. También se ha postulado que la TP, por un mecanismo de sensibilización de las células endoteliales de la vasculatura pulmonar, produciría un aumento en los niveles de AMPc resultando en vasoconstricción de estos vasos ${ }^{85}$.

La asociación entre hiperleucocitosis y desarrollo de HTP refractaria es otra de las hipótesis postuladas. La TP es un conocido factor promotor de leucocitosis periférica, y en forma indirecta refleja también la cantidad de bacterias implicadas ${ }^{75,79,86}$. Esto generaría el desarrollo de trombos microvasculares lo que asociado a un sistema de coagulación y fibrinolítico inmaduro, generaría un síndrome de hiperviscosidad sanguínea y trombosis de las arteriolas pulmonares ${ }^{80,81,87}$.

Sin embargo, otros autores postulan que tras la HTP existiría un proceso vasculítico local, más que un vasoespasmo, secundario al daño del epitelio respiratorio y progresivamente del endotelio vascular, mediado por citoquinas liberadas desde los linfocitos ${ }^{27,28}$. No obstante, debemos destacar que aún no es bien comprendida en su totalidad la fisiopatología de la HTP.

Otro hallazgo a considerar es el desarrollo de síndrome de disfunción orgánica múltiple (SDOM) en el contexto de la CG, además de las causas habituales de éste (disoxia originada por shock); la TP tiene efectos inmunomoduladores, tanto en la población como en el fenotipo de las células $\mathrm{T}$ y en las inmunoglobulinas ( $\mathrm{IgE}, \operatorname{IgA}$ e $\operatorname{IgG})^{88-91}$. Reportes sugieren que hay pérdida de la actividad de la L-selectina, la cual es responsable de la adhesión de linfocitos, neutrófilos y monocitos al endotelio vascular activado por citoquinas en los sitios de inflamación ${ }^{92-94}$, generando de esta forma un estado de inmunoparálisis relativo y presencia de SDOM en los pacientes con CG. Además puede originar apoptosis linfocitaria y secundariamente falla orgánica múltiple ${ }^{95,96}$.

Otros autores sugieren que existe una disrupción en la transducción de señales del ciclo celular en el sistema de la proteína $\mathrm{G}$, alterando la respuesta celular al estrés ${ }^{97}$, generando un punto de "no retorno" o irreversibilidad en la falla orgánica múltiple ${ }^{98}$.

Durante la infancia, la apoptosis de las células epiteliales pulmonares es un mecanismo crucial en el daño pulmonar agudo ${ }^{99}$. En la CG este fenómeno puede verse exacerbado, lo que quedó demostrado en el trabajo de Paddock y cols. ${ }^{80}$, donde los hallazgos de extensa denudación del epitelio bronquiolar y alveolar con células apoptóticas sugieren que este mecanismo está implicado en la patogenia del curso grave de esta enfermedad.

\section{Hallazgos histopatológicos}

Actualmente, existen escasos reportes de las características histopatológicas de la coqueluche fatal y además ninguno de ellos explica a cabalidad las características fisiopatológicas de la HTP secundaria observada.

Desde principio del siglo XX, las descripciones han enfatizado el extenso compromiso de las vías áreas, desde tráquea hasta alvéolos, demostrando gran cantidad de $B$. pertussis en los cilios de la mucosa traqueal y bronquial, con daño de este epitelio ${ }^{100}$. Esto concuerda con los hallazgos de Paddock y cols., quienes en una reciente comunicación identificaron este patógeno, en forma intacta, en el citoplasma de las células ciliadas del epitelio columnar. Tanto en la tráquea como en los bronquios se describe un gran daño de la mucosa, con pérdida ciliar, epitelio denudado y metaplasia escamosa ${ }^{80}$.

Se ha detallado una secuencia de eventos histopatológicos, en el cual la endobronquitis y endobronquiolitis evolucionan a peribronquitis, peribronquiolitis y bronconeumonía difusa ${ }^{101,102}$. El daño bronquiolar y alveolar se caracteriza por la presencia de necrosis del epitelio, formación de membranas hialinas e infiltrado pulmonar, compuesto principalmente por macrófagos alveolares con $B$. pertussis en su interior, lo cual contribuiría a la formación de secreciones espesas que son características de esta enfermedad.

En relación a la patogénesis de la HTP aún no está dilucidada. Se ha propuesto que el daño del epitelio alveolar y bronquial mediado por toxinas podría llevar a un aumento de la resistencia de la vasculatura pulmonar y el subsecuente desarrollo de HTP ocasionando finalmente colapso cardio-circulatorio ${ }^{76}$. No obstante, también se ha reconocido la asociación entre la magnitud de la leucocitosis presentada por el paciente y la gravedad de la enfermedad, siendo valores de leucocitosis extremas $\left(>100.000 / \mathrm{mm}^{3}\right)$ un factor pronóstico independiente ${ }^{75}$.

Halasa y cols. ${ }^{85}$, describieron la presencia de trombos leucocitarios en arterias pulmonares de un lactante con coqueluche, quién desarrolló leucocitosis extrema y requirió soporte extracorpóreo con ECMO. Pierce y cols. $^{75}$, atribuyen la causa de HTP en cuatro de sus casos a obstrucción vascular, aunque su hipótesis no fue confirmada por biopsia pulmonar. Sawal y cols. ${ }^{76}$, reportaron la presencia de formaciones trombóticas compuestas por linfocitos y neutrófilos en venas y arterias pulmonares de mediano y pequeño calibre. Esto se contrapone a los hallazgos de Paddock y cols. ${ }^{80}$, los cuales observaron agregados leucocitarios en arteriolas y vénulas pero no la presencia de trombosis pulmonar. La exclusiva presencia de leucocitos en el lumen vascular no es suficiente eviden- 
cia de trombosis, ya que ésta es una característica común de observar en pacientes con infección fatal ${ }^{76}$.

Se ha propuesto, entonces, que la HTP demostrada en algunos pacientes no es sólo explicable por la presencia de leucostasia, sino que su patogénesis estaría dada por la combinación de leucostasia y daño vascular pulmonar ${ }^{76}$. A favor que sólo la leucocitosis sería el único factor desencadenante de la HTP, recientes reportes han demostrado una mejoría significativa de la hipoxemia luego de la utilización de procedimientos de leucoreducción como exanguino-transfusión o leucoféresis ${ }^{87,103}$. La buena respuesta a estas terapias podría ser explicada parcialmente por la disminución de la viscosidad sanguínea, la cual puede reducir la formación de microtrombos y la adhesión de leucocitos activados al endotelio vascular con la subsecuente obstrucción. Dado que $B$. pertussis puede permanecer en el interior de los macrófagos más de 40 días $^{80}$, estos procedimientos difícilmente pueden eliminar completamente las toxinas de la bordetela; así, parece probable que la rápida respuesta clínica observada sea el resultado de una disminución de la masa leucocitaria ${ }^{65}$.

Otro hallazgo descrito por Sawal y cols. ${ }^{76}$, es la reducción linfocitaria en bazo, ganglios y timo. De los 10 casos mencionados en su trabajo, ocho presentaron en el timo disminución cortical con reducción del peso, siete mostraban grave reducción linfocitaria sin reacción folicular en ganglios y nueve presentaron intensa disminución de la pulpa blanca esplénica. Sugimoto y cols. ${ }^{104}$, reportaron que el factor promotor de linfocitosis actúa directamente sobre las células linfoides del timo causando inmunodepresión, lo cual años más tardes fue comunicado por Smith y Vyas $^{105}$ en cuatro casos post-mortem de coqueluche. Esta condición junto a la inmunoparálisis provocada por la $\mathrm{TP}$, hace que estos pacientes sean vulnerables a presentar co-infecciones y a su vez sean incapaces de controlar la infección primaria del epitelio bronquial.

En conclusión, B. pertussis tiene un efecto devastador en las vías aéreas y tejido pulmonar. A futuro será necesario incluir pruebas de mayor complejidad orientadas a dilucidar los mecanismos inmunopatogénicos que ocasionan el extenso daño del epitelio bronquial y alveolar como también a la documentación de pruebas de función linfocitaria.

\section{Tratamiento antimicrobiano}

La susceptibilidad antimicrobiana de $B$. pertussis ha sido extensamente estudiada in vitro ${ }^{106}$, mostrando una excelente concentración inhibitoria mínima ante los macrólidos, azálidas como también las fluoroquinolonas ${ }^{107}$. Entre los macrólidos, eritromicina ha sido estudiada in vivo siendo su eficacia para erradicar este patógeno de la nasofaringe demostrada ${ }^{108}$. Los nuevos macrólidos y azálidas (claritromicina y azitromicina), han demostrado una penetración intracelular elevada y sostenida, por lo que son particularmente efectivos contra $B$. pertussis. Ambas son más resistentes al ácido gástrico logrando mayores concentraciones tisulares, tienen mayor vida media por lo que pueden administrarse en forma menos frecuente y en menor número de días, lo que permite mayor adherencia al tratamiento ${ }^{59}$.

Dos observaciones en el campo del tratamiento antimicrobiano de la coqueluche deben destacarse, estas son: a pesar de reportes escasos y más bien anecdóticos de cepas resistentes a eritromicina (Estados Unidos y Taiwán) ${ }^{109-112}$, las pruebas de sensibilidad antimicrobiana no se realizan con fines asistenciales, ya que es un microrganismo fastidioso y su cultivo es lento y engorroso; debería realizarse sólo en cepas seleccionadas y como parte de un sistema regional de vigilancia. El mecanismo de resistencia propuesto es por mutación en el sitio de unión de eritromicina en el gen 23S de ARNr, y la identificación de éste y otros potenciales mecanismos de resistencia permitiría evaluar el genotipo y facilitar un screening más rápido de un gran número de cepas aisladas ${ }^{113}$. Desde hace 30 años ha sido recomendado el tratamiento por 14 días; sin embargo, la erradicación bacteriana ocurre dentro de los 5 días de iniciada la terapia, acortando el período de contagio habitual que puede ser hasta 4 semanas ${ }^{1,27,38}$. Se ha demostrado igual eficacia de eritromicina estolato con una duración de tratamiento de siete días comparado con catorce días ${ }^{114}$. Actualmente, la recomendación de la Academia Americana de Pediatría es de 14 días en Estados Unidos, pero el otras latitudes como Canadá, Inglaterra, Australia, Nueva Zelandia, se recomienda usar 7 días de eritromicina.

Estudios clásicos mostraron que el beneficio principal de eritromicina para los pacientes es en la fase catarral, reduciendo la gravedad y duración de la enfermedad ${ }^{27,60,115,116}$. Resultados controversiales se han obtenido cuando el tratamiento se inicia en la fase paroxística. Un único estudio efectuado en Alemania ${ }^{117}$ reportó disminución de la intensidad de la tos mientras que otras comunicaciones no encontraron efectos ${ }^{118-120}$, aunque recomiendan su uso para limitar la diseminación del patógeno ${ }^{121}$.

En la Tabla 2 se exponen las recomendaciones de la Academia Americana de Pediatría en relación a tratamiento y profilaxis antimicrobiana de la coqueluche.

Los macrólidos (eritromicina, claritromicina) y azitromicina (estrictamente una azálida) son los antimicrobianos de primera línea para el tratamiento y profilaxis en los pacientes sobre seis meses de edad; en lactantes bajo esta edad la elección del tratamiento antimicrobiano requiere especial atención. La FDA no ha aprobado el uso de azitromicina y claritromicina en estos pacientes, pero desde el año 2006 la Academia Americana de Pediatría recomienda el uso de azitromicina en los lactantes bajo seis meses por el riesgo de estenosis hipertrófica del píloro 


\begin{tabular}{|c|c|c|c|c|}
\hline \multirow[b]{2}{*}{ Edad } & \multicolumn{3}{|c|}{ Antimicrobianos recomendados } & \multirow{2}{*}{$\begin{array}{l}\text { Alternativa } \\
\text { TMP-SMX }\end{array}$} \\
\hline & Azitromicina & Eritromicina & Claritromicina & \\
\hline$<1$ mes & 10 mg/kg día por 5 días & $\begin{array}{l}40-50 \mathrm{mg} / \mathrm{kg} / \text { día dividida en } \\
4 \text { dosis por } 14 \text { días }\end{array}$ & No recomendada & Contraindicada bajo 2 meses de edad \\
\hline $1-5$ meses & Ver arriba & Ver arriba & $\begin{array}{l}15 \text { mg/kg/día dividida en } \\
2 \text { dosis por } 7 \text { días }\end{array}$ & $\begin{array}{l}\geq 2 \text { meses: TMP } 8 \text { mg/kg/día; SMX } 40 \\
\text { mg/kg/día dividida en } 2 \text { dosis por } 14 \text { días }\end{array}$ \\
\hline$>6$ meses y niños & $\begin{array}{l}10 \text { mg/kg en una dosis el día } 1 \text { (máximo } \\
500 \text { mg); luego } 5 \text { mg/kg en una dosis del } \\
\text { día 2-5 (máximo } 250 \mathrm{mg} / \mathrm{kg} \text { ) }\end{array}$ & $\begin{array}{l}\text { Ver arriba } \\
\text { (máximo } 2 \text { g/día) }\end{array}$ & $\begin{array}{l}\text { Ver arriba } \\
\text { (máximo } 1 \text { g/día) }\end{array}$ & Ver arriba \\
\hline $\begin{array}{l}\text { Adolescentes y } \\
\text { adultos }\end{array}$ & $\begin{array}{l}500 \text { mg dosis única en el día } 1 \text { y luego } \\
250 \text { mg dosis única del día } 2-5\end{array}$ & $\begin{array}{l}2 \text { g/día dividida en } 4 \text { dosis } \\
\text { por } 14 \text { días }\end{array}$ & $\begin{array}{l}1 \mathrm{~g} / \text { día dividida en } \\
2 \text { dosis por } 7 \text { días }\end{array}$ & $\begin{array}{l}\text { TMP } 320 \text { mg/día; SMX } 1.600 \text { mg/día divi- } \\
\text { dido en } 2 \text { dosis por } 14 \text { días }\end{array}$ \\
\hline
\end{tabular}

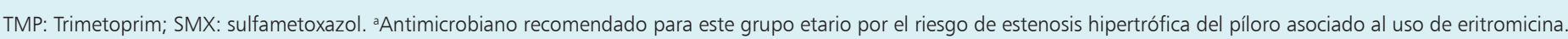

asociada al uso de eritromicina ${ }^{121}$ aunque recientemente se han reportado dos casos asociados a azitromicina ${ }^{122}$. En caso de intolerancia a los macrólidos, está indicado el uso de cotrimoxazol ${ }^{121}$.

Se estima que la enfermedad se produce en prácticamente $90 \%$ de los contactos susceptibles, por lo

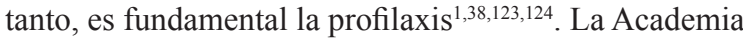
Americana de Pediatría recomienda la quimioprofilaxis en todos los contactos del grupo familiar directo u otros contactos directos, independiente de su edad y estado de vacunación. El fundamento de esta recomendación es que la administración de la profilaxis a los contactos asintomáticos dentro de los 21 días del inicio de la tos en el paciente índice puede limitar la transmisión secundaria $^{121}$; sin embargo, otros países como Australia ${ }^{125}$, Reino Unido $^{126}$ y Canadá ${ }^{127}$ limitan el uso de antimicrobianos profilácticos a los contactos que presentan factores de riesgo para el desarrollo de complicaciones. Actualmente, en nuestro país las indicaciones de quimioprofilaxis son las siguientes ${ }^{128}$ :

"Miembros del grupo familiar directo, es decir, a personas que duermen bajo el mismo techo que el enfermo". De éstos, sólo se considerarán aquellos contactos con riesgo de enfermedad grave o complicada:

- Lactantes bajo un año de edad, independiente de su estado de inmunización.

- Lactantes hasta los dos años de edad con esquema de vacunación menor a tres dosis.

- Mujeres embarazadas en el último trimestre.

- Adultos mayores de 65 años.

- Niños y adultos con afecciones cardiopulmonares crónicas con capacidad funcional limitada.

- Hospitalizados en la misma sala que el caso, que no cumplan con la distancia de un metro entre camas o cunas.

- Personal de salud y profesorado expuesto al riesgo, sólo en caso de brotes.

\section{Enfoque terapéutico del paciente con coqueluche grave}

Todo neonato y lactante bajo 3 meses de edad, con sospecha de coqueluche, debe ser hospitalizado y someterse a observación, en caso de confirmarse la presencia de $B$. pertussis en su nasofaringe, por un período de 5 a 7 días hasta descartar una evolución complicada. El paciente con CG o con sospecha de éste, requiere monitorización en una unidad de cuidados intensivos.

Habitualmente los pacientes evolucionan con síndrome de distress respiratorio agudo, asociado a signos de falla miocárdica aguda. Las evidencias clínicas de HTP son súbitas e impredecibles, por lo que se debe tener un alto índice de sospecha. Es indispensable establecer una adecuada monitorización invasora y uso de ecocardiografía para confirmar o no la presencia de HTP.

El tratamiento fundamental es de soporte, manteniendo una oxemia y hemodinamia adecuada, con presión arterial media (PAM) sobre el nivel de la presión arterial media pulmonar (PAMP), intentando mantener una resistencia vascular pulmonar baja y, de no ser esto posible, aumentar la resistencia vascular sistémica, manteniendo una presión de perfusión adecuada ${ }^{54}$. En la Figura 1 se muestra un algoritmo terapéutico, el cual es utilizado en nuestra unidad. Los principales tópicos se discuten a continuación:

\section{Hemodinamia}

La resucitación con fluidos es la terapia de primera línea en búsqueda de optimizar la hipoperfusión ocasionada por el hipodébito, pues la mantención del shock es de muy mal pronóstico, produciéndose una escalada con un mayor deterioro hemodinámico al aumentar la acidosis y la hipoxemia ${ }^{8,82,85,87,129}$.

Los fármacos vasoactivos a utilizar de preferencia son las catecolaminas con efecto inotrópico como dobutamina 
o epinefrina y/o fármacos inodilatadores ${ }^{79,130}$ como los inhibidores de la fosfodiesterasa III, siendo la milrinona la opción a elegir, pues ofrece una opción terapéutica en esta situación de insensibilidad adrenérgica ${ }^{40}$, ya que sus efectos no son inhibidos por la $\mathrm{TP}^{131}$.

Levosimendan, es un nuevo fármaco inotrópico y vasodilatador que actúa aumentando la respuesta de los cardiomiocitos al calcio, mediante la sensibilización de la troponina $\mathrm{C}$ y abre los canales de potasio dependientes de $\mathrm{ATP}^{132}$, lo cual lo convierte en una interesante opción terapéutica en shock cardiogénico, al mejorar la contractibilidad sin alterar la miorrelajación ni aumentar el consumo de oxígeno cardíaco. Si bien aún su uso es muy limitado en niños, resultados experimentales y en adultos son promisorios ${ }^{131}$.

La alcalinización sistémica a niveles de $\mathrm{pH}$ sanguíneo hasta 7,5 debe instaurarse mediante el aporte de bicarbonato según se requiera, monitorizando los niveles de electrolitos plasmáticos.

\section{Ventilación mecánica (VM)}

La conexión debe ser precoz ya que la VM debe ser vista como parte del tratamiento del paciente en shock cardiogénico, no esperando la aparición de hipoxemia evidente, ya que la presencia de ésta es un signo ominoso, que asociada a acidosis aumentará el tono de la vasculatura pulmonar. En nuestra experiencia el uso de ventilación de alta frecuencia oscilatoria (VAFO) debe ser instaurado en forma temprana ${ }^{86,129}$ ya sea por hipoxemia grave persistente o bien por hipercapnia refractaria a uso de VM convencional. Es importante recordar que si existe HTP la hiperventilación debe ser moderada manteniendo la $\mathrm{PaCO}_{2}$ entre $30-35 \mathrm{mmHg}$, ya que valores inferiores son deletéreos.

Es importante un adecuado nivel de sedoanalgesia y considerar precozmente el inicio de relajantes neuromusculares en este contexto clínico.

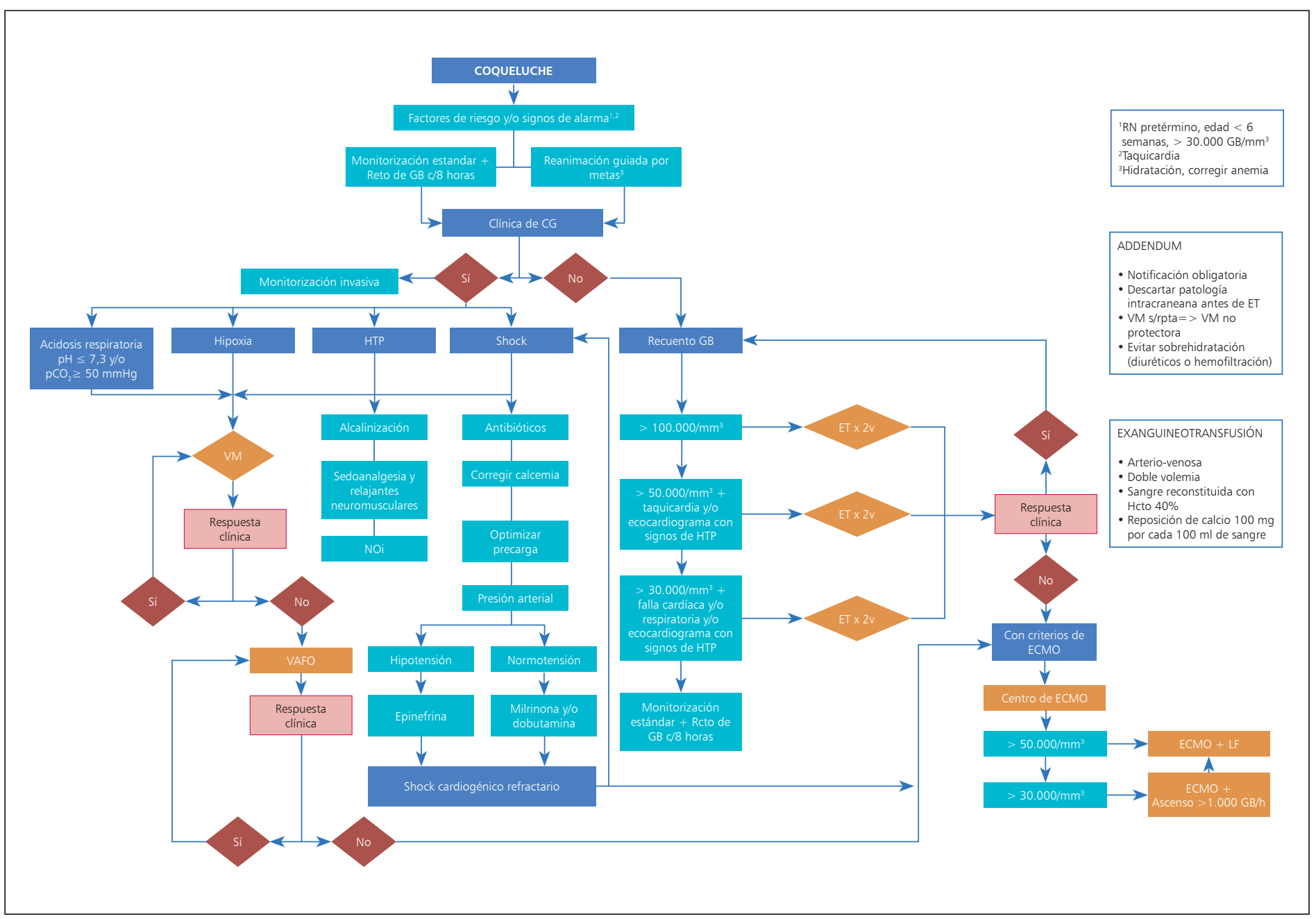

Figura 1. Algoritmo terapéutico para coqueluche grave. Hospital Padre Hurtado 2011 (Donoso, Arriagada, Cruces, Díaz, Ramírez, León). 


\section{Tratamiento antimicrobiano de la sobreinfección}

La sobreinfección bacteriana es frecuente en estos pacientes. Debido a ello, agregamos a la terapia con macrólidos, esquemas con cobertura para otros patógenos respiratorios propios de la comunidad y eventualmente nosocomiales, recomendando en nuestra institución: ampicilina y cefotaxima en pacientes bajo seis semanas de edad y cefotaxima y cloxacilina sobre esa edad ${ }^{7,69,71}$.

\section{Óxido nítrico inhalado (NOi)}

A diferencia de su indiscutible rol en hipertensión pulmonar persistente neonatal (HTPPN), los resultados en HTP en CG no han sido satisfactorios $78,81,85,133,134$. El óxido nítrico (NO), o factor relajador derivado del endotelio, se produce por diversos estímulos que activan la enzima NOS 1,27,133. El NO junto con el fierro como cofactor, activa la enzima guanilato ciclasa, estimulándola para producir GMP cíclico, que produce la liberación de neurotransmisores que llevan a la relajación del músculo liso y vasodilatación ${ }^{27,38,40}$.

En la CG una vez establecida la HTP y la hipoxemia grave, las opciones de tratamiento son muy limitadas. El uso de NOi ha sido descrito ocasionalmente ${ }^{81,134}$; sin embargo, no hay reportes publicados de respuesta hemodinámica satisfactoria o mejoría de la oxigenación clínicamente significativa, e incluso podría empeorar los efectos de la citotoxina traqueal. Heiss y cols., ${ }^{135,136}$ han demostrado que la toxicidad de la citotoxina traqueal se debe a la inducción de las células hospederas para la producción de interleuquina-1 (IL-1), la cual activa la enzima NOS, lo que conduce a altos niveles de radicales libres de NO. Los efectos citotóxicos del NO radican en la capacidad de depletar el hierro intracelular e inhibir a las enzimas dependientes de hierro necesarias para la respiración mitocondrial y síntesis de $\mathrm{ADN}^{137}$. Además, considerando que se postula que una de las causas de la hipoxemia y la HTP observada es la formación de trombos leucocitoclásticos en la vasculatura pulmonar, es de esperar que el uso de NOi presente un escaso efecto vasodilatador $^{87}$.

\section{Vasodilatores pulmonares}

El sildenafilo es un inhibidor de la fosfodiesterasa tipo $\mathrm{V}$ que bloquea la degradación del GMPc produciendo un efecto vasodilatador. Su utilidad ha sido reportada en varias patologías asociadas a HTP, principalmente en HTP primaria y en neonatos para el destete del NOi. Como hemos señalado, el efecto vasodilatador del NOi se produce al aumentar los niveles de GMPc, por lo tanto, la asociación de estos dos fármacos podría tener un efecto sinérgico como vasodilatador pulmonar ${ }^{138}$, lo cual quedó demostrado por Soares y cols. ${ }^{139}$, en un caso de un neonato de seis días de vida que cursó con CG, en el cual se utilizó ambas terapias observando una mejoría en la oxigenación y permitió un destete progresivo del $\mathrm{NOi}$, con sobrevida del paciente. Actualmente, la dosis óptima de sildenafilo no está determinada en la población infantil, pero es probable que el rango sea entre 0,3 y $1 \mathrm{mg} / \mathrm{kg}$ tres veces al día ${ }^{140}$.

Sin embargo, tal como fue discutido previamente, el desbalance que se produce entre vasoconstrictores y vasodilatadores en esta patología, probablemente no es sólo cuantitativo, sino que involucra una alteración a nivel molecular, de segundos mensajeros, recordando que tal vez el exceso de NOi pudiera ser deletéreo ${ }^{27,81,87}$.

Otros vasodilatadores como los antagonistas de endotelina-1, (bosentan, ambrisentan) análogos de la prostaciclina (iloprost, epoprostenol), péptido natriurético tipo B recombinante (nesiritide) no han sido evaluados en el contexto clínico de una CG.

Finalmente, debemos destacar que luego del desarrollo de hipoxemia refractaria por HTP la respuesta a vasodilatadores pulmonares es excepcional $1^{8,79,81,87,129,133}$.

\section{Soporte vital extracorpóreo (Extra Corporeal Membrane Oxygenation- ECMO)}

A diferencia de lo reportado en HTPPN ${ }^{141}$, los resultados de ECMO en CG han sido decepcionantes. La sobrevida comunicada es sólo cercana a $40 \%$, un porcentaje menor al compararlo con la mortalidad general de los pacientes ingresados a ECMO por otras causas, lo que ha llevado a algunos autores a cuestionar su uso ${ }^{78,81,85,133,134}$.

Halasa y cols..$^{85}$, realizaron un análisis crítico de los registros de la Extracorporeal Life Support Organization (ELSO), entre los años 1986 y 2002, en pacientes con CG, buscando factores de riesgo de mortalidad en ECMO. La mortalidad en lactantes bajo seis semanas de vida fue $84 \%$, mientras que en los mayores fue de $61 \%$.

Hasta el año 2009, este registro tiene 169 casos de CG con una tasa de mortalidad de $69,8 \%$, mucho mayor que otras patología respiratorias, incluida la neumonía por virus respiratorio sincicial (tasa de 20\%). Los lactantes bajo seis semanas de edad tienen la mayor tasa de mortalidad $(83,6 \%)^{77}$ siendo similar a la reportada hace algunos años.

Inwald y cols. ${ }^{142}$, demostraron la utilidad clínica de la realización de biopsia pulmonar a cielo abierto en 15 pacientes sometidos a ECMO. De éstos, tres pacientes cursaron con SDRA secundario a CG y en todos se demostraron hallazgos histológicos de infarto pulmonar. En consecuencia, en aquellos pacientes que cursen con 
CG y no se observe mejoría luego de estar 3-4 semanas en ECMO podría considerarse la biopsia pulmonar y así determinar la presencia de tejido viable.

En nuestra opinión, en el caso que sea disponible la terapia con ECMO, debiera ser una opción a considerar, no obstante teniendo una visión de su real utilidad.

\section{Terapias de leucorreducción}

\section{Exanguino-transfusión}

La presencia de hiperleucocitosis, definida como valores mayores a $10^{5} / \mathrm{mm}^{3}$ ha sido descrito como factor de riesgo de muerte en $\mathrm{CG}^{75,85}$, atribuyéndose al síndrome de hiperviscosidad un rol al ocasionar un factor mecánico obstructivo por el desarrollo de trombos leucocitoclásticos en la vasculatura pulmonar, similar a lo que se ha descrito para otras enfermedades ${ }^{144}$.

Utilizando esta hipótesis, se ha propuesto a la exanguino-transfusión (ET) como un procedimiento destinado a reducir la cantidad de leucocitos circulantes y de este modo disminuir el probable efecto mecánico en los vasos pulmonares. El resultado que pudiera tener esta terapia en reducir la magnitud de la toxemia por TP no ha sido estudiado, pero llama la atención que los pacientes presentan habitualmente luego de la ET un efecto de rebote en el recuento leucocitario que usualmente condiciona la repetición del procedimiento ${ }^{79,86}$. Luego de este segundo recambio el ascenso ha sido mucho menor, lo que pudiera ser explicado por el efecto de "arrastre" de la toxina durante los recambios repetitivos.

A la fecha de la presente revisión, hay publicados siete reportes de casos, con un total de 16 pacientes, en quienes se empleó terapia de leucodepleción (Tabla 3).

Romano y cols..$^{87}$, comunicaron el primer caso exitoso de ET en un niño de tres meses de edad, demostrando una mejoría en la oxigenación luego del procedimiento y caída de los signos indirectos de HTP. Recientemente Martínez y cols. ${ }^{65}$, reportaron el caso de una lactante de 8 semanas, quien presentaba todos los factores de riesgo asociados con una elevada mortalidad como eran: edad, calendario de vacunación incompleto, neumonía, convulsiones e hiperleucocitosis de $119.000 / \mathrm{mm}^{3}$ en la cual se utilizó esta terapia con resultados favorables, observando una mejoría clínica asociada a una reducción significativa del recuento leucocitario. Por el contrario, Berthomieu y cols. ${ }^{66}$, publicaron la falla de este tratamiento, utilizado en un lactante de un mes con HTP isosistémica. Esto sugiere que la ET es beneficiosa en pacientes con CG que cursan con hiperleucocitosis pero muy probablemente si esta es utilizada tempranamente en el curso de la enfermedad.

\section{Leucoféresis}

La patogénesis de la HTP descrita en la coqueluche es aún desconocida, pero se postula que la leucocitosis grave (recuento de leucocitos $>10^{5} / \mathrm{mm}^{3}$ ) condicionaría la formación de trombos leucocitoclásticos en la vasculatura pulmonar. Esto generaría una hipoxemia grave, progresiva y refractaria al tratamiento de soporte, con una muy pobre respuesta a las diferentes modalidades de ventilación mecánica $^{40,87,144}$, NOi y terapia de soporte extracorpóreo como $\mathrm{ECMO}^{85,134}$, lo que ha condicionado una alta mortalidad en los pacientes que ingresan a unidades de cuidados intensivos pediátricos $(50-70 \%)^{105}$.

Basándose en la hipótesis que la leucostasia en la vasculatura pulmonar es un factor responsable en el desarrollo de HTP y falla hemodinámica, se ha propuesto el uso de terapias de leucoreducción como una opción terapéutica a considerar.

En relación al uso de este procedimiento en CG, no existen grandes series clínicas como tampoco cohortes descriptivas, sino que sólo casos clínicos con diferentes grados de eficacia. Grzeszczak y cols. ${ }^{103}$, en el año 2006, comunicaron el caso de un lactante de cinco semanas con $\mathrm{CG}$, que rápidamente presentó deterioro clínico, con hallazgos ecocardiográficos de HTP. Se inició ECMO y tres horas después leucoféresis, presentando una notable mejoría clínica, asociada temporalmente a una disminución del recuento leucocitario.

Recientemente, Rowland y cols. ${ }^{77}$, reportaron diecinueve pacientes bajo tres meses de edad, con diagnóstico confirmado de CG, que se hospitalizaron en UCI, donde once de estos pacientes requirieron ECMO, en el período comprendido entre los años 2001 y 2009. Se comparó la reducción del recuento leucocitario y la tasa de mortalidad en dos período (2001-2004 y 2005-2009). En el último de éstos, en el cual se utilizó ECMO asociado a leucofiltración, el recuento leucocitario (promedio 75.000/. $\mathrm{mm}^{3}$ ) disminuyó en $83 \%$ a las 10 horas de iniciada la terapia y la mortalidad se redujo a $10 \%$ en comparación con el primer período, en el cual se empleó exclusivamente ECMO, donde la reducción del recuento leucocitario (promedio $52.000 / \mathrm{mm}^{3}$ ) disminuyó en $55 \%$ a las 10 horas de iniciada la terapia y la mortalidad fue de $45 \%$.

Con estos hallazgos, la utilización de leucoféresis en forma precoz, debe considerarse una opción terapéutica en aquellos pacientes con CG que cursan con leucocitosis extrema.

\section{Uso de inmunoglobulina}

Debido al importante papel de la TP en los efectos sistémicos de la enfermedad surgió la idea de instaurar como opción terapéutica el bloquear la acción de esta toxi$\mathrm{na}^{27}$. Múltiples ensayos clínicos intentaron demostrar una disminución en la duración e intensidad de los síntomas con el uso de inmunoglobulina humana, pero a diferencia de lo observado in vitro y en modelos experimentales 


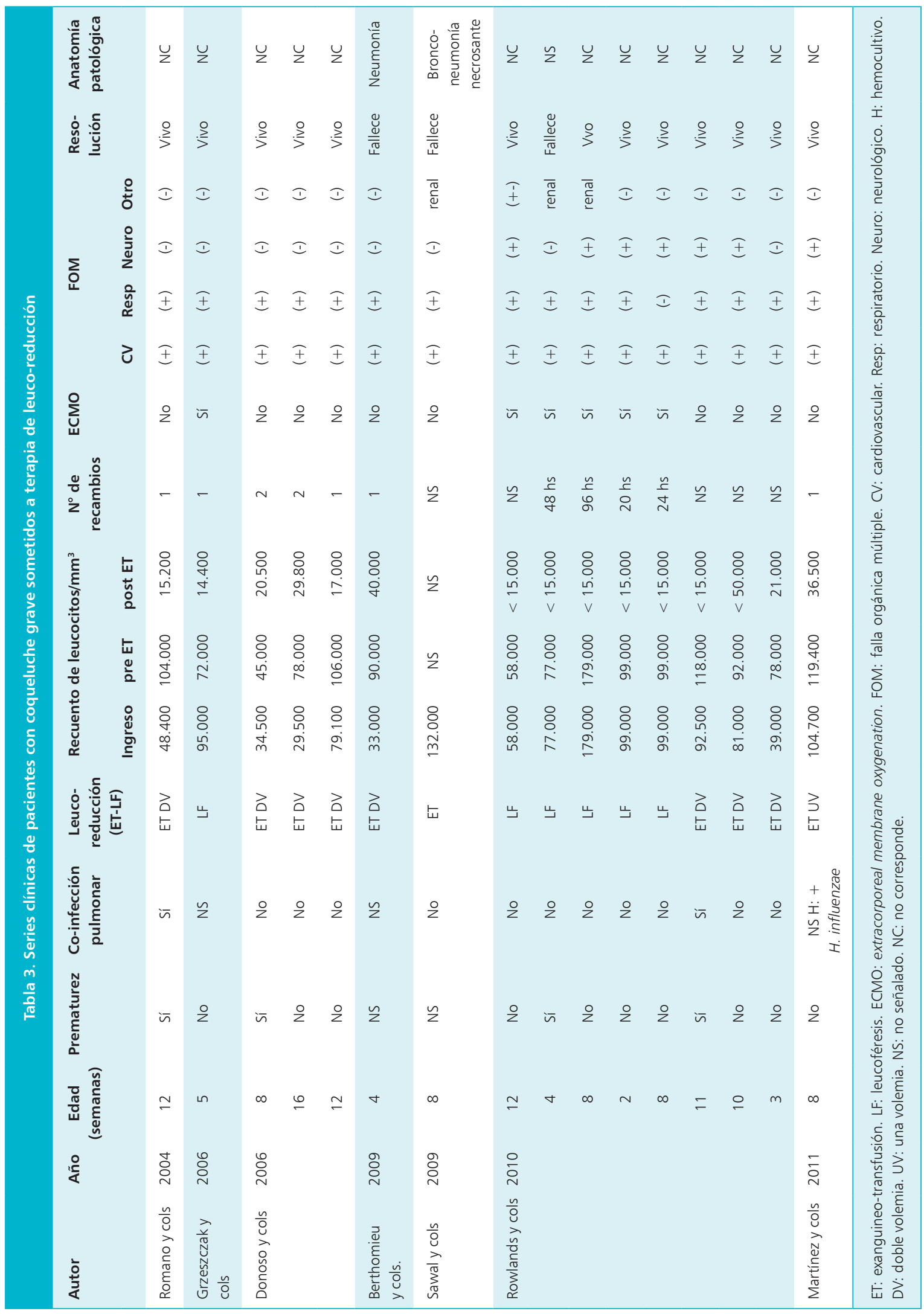


animales, ninguno logró corroborar tal efecto $^{27,145}$. En parte apoyado por estos resultados, muchos investigadores plantearon que la toxina se uniría en forma irreversible a su efector, por lo tanto, una vez iniciada la fase de estado de la enfermedad, no se obtendría beneficio del bloqueo de su actividad. Granstrom y cols. ${ }^{146}$, y luego Bruss y cols. $^{147,148}$, lograron demostrar en dos ensayos clínicos independientes un efecto beneficioso con la administración de inmunoglobulina anti-TP. Ambos autores plantean que el problema principal de los estudios anteriores era la baja concentración de anticuerpos específicos anti-TP. Así Bruss y cols. ${ }^{148}$, en un modelo experimental murino, logró demostrar una mayor sobrevida y disminución de síntomas sistémicos asociada a un descenso significativo de la leucocitosis en el grupo tratado con gammaglobulina hiperinmune anti-TP.

En el año 2006, Halperin y cols. ${ }^{149}$, realizaron un estudio clínico, fase 3, multicéntrico, aleatorio, placebo controlado, en el cual evaluaron la eficacia en la mejoría de síntomas de la inmunoglobulina anti TP intravenosa (P-IGIV). Para tal efecto se ingresaron 25 pacientes bajo 5 años de edad (17 grupo P-IGIV y 8 grupo placebo) durante dos años, con diagnóstico de coqueluche. No se logró demostrar diferencia alguna entre ambos grupos, lo que se contrapone a los resultados obtenidos en los trabajos mencionados anteriormente ${ }^{146,147}$. Sin embargo, el estudio de Halperin y cols., fue terminado precozmente por el bajo reclutamiento de pacientes. Este sesgo determina que el estudio no pueda confirmar o refutar el beneficio de la inmunoglobulina anti-TP.

En nuestro sentir, el uso empírico de inmunoglobulina humana no específica, no está indicada en estos pacientes, más aún hay que conocer las concentraciones de anticuerpos anti-TP en las preparaciones disponibles como también el incentivar el desarrollo de preparaciones con alta concentración para promover ensayos clínicos que demuestren o descarten su utilidad.

\section{Inmunización en adolescentes y adultos}

Como ya se mencionó, desde mediado de la década de los 90 se ha observado un aumento en los números de casos, principalmente en lactantes bajo seis meses de edad, adolescentes y adultos ${ }^{150}$. Este fenómeno podría explicarse por mejoría en los métodos diagnósticos disponibles, reconocimiento por los médicos de esta enfermedad en adolescentes y adultos y en la mejoría de las notificaciones. Sin embargo, el incremento real de los casos en este grupo etario ha ocurrido por una pérdida de la inmunidad.

La enfermedad estimula la formación de anticuerpos humorales contra diversos factores de virulencia como también una respuesta de la inmunidad celular. Si bien, no hay marcadores específicos de protección contra la enfermedad, existe cierta correlación entre los niveles circulantes de anticuerpos contra TP, HF, PRN, FIM y la presencia de inmunidad ${ }^{9}$. Esta correlación fue observada en el estudio realizado por Van der Wielen y cols. ${ }^{151}$, quienes analizaron suero de personas belgas sanas, describiendo pérdida de inmunidad especifica anti pertussis, observándose una caída significativa de anticuerpos anti TP-PRN a medida que transcurrían los años, aumentando la susceptibilidad de los adultos a la enfermedad.

La duración de la inmunidad adquirida por infección va desde un rango de 7 a 20 años ${ }^{152,153}$. Este amplio rango podría ser consecuencia de diferentes niveles circulantes de $B$. pertussis, los sistemas de vigilancia o definición de caso usado. Con respecto a la inmunidad adquirida por vacuna, tanto celular como acelular, ésta empieza a disminuir después de 3 a 5 años, y no existe protección demostrable después de los $10-12$ años ${ }^{154}$. Con la vacuna DTP acelular (Tdap) no se ha determinado aún la duración de la protección, pero los valores de anticuerpos postvacunación sugieren que ésta dura entre 5 y 10 años ${ }^{154}$. Recientes estudios epidemiológicos han demostrado que la inmunidad natural después de la infección no es mayor que la adquirida por inmunización ${ }^{154}$, y a su vez no existen diferencias entre ambas vacunas ${ }^{155}$.

Como consecuencia, los adolescentes y adultos jóvenes se han transformado en una fuente de transmisión entre sus pares y lactantes menores; por ende, la vacunación en este grupo sería una buena estrategia para reducir las tasas de morbilidad y los casos en lactantes, al disminuir la fuente de contagio que representan ambos grupos ${ }^{150}$.

En Chile, Perret y cols. ${ }^{156}$, realizaron un estudio multicéntrico, donde se determinó la fuente infectante de 10 lactantes hospitalizados por coqueluche. En $80 \%$ de los casos ésta fue al interior del grupo familiar y de éstos, $90 \%$ correspondió a adolescentes y adultos vacunados, lo cual confirmaría la pérdida de protección de la vacuna con el tiempo.

Desde el año 2005, la FDA aprobó dos vacunas acelulares: Adacel ${ }^{\circledR}$ (aplicable desde los 11 a 64 años) y Boostrix ${ }^{\circledR}(10$ a 18 años). Ambas vacunas contienen toxoide diftérico y tetánico más antígenos inmunoestimulantes y protectores para $B$. pertussis, como son: TP, hemaglutinina filamentosa (HAF) y PRN, más aglutinógenos de fimbrias en el caso de Adacel ${ }^{\circledR}$. Sus componentes están en dosis más bajas que en las vacunas acelulares que se usan en niños bajo 7 años ${ }^{155,157}$. Todos los estudios han demostrado una adecuada inmunogenicidad, perfil de seguridad así como una buena eficacia ${ }^{158,159}$.

Adacel ${ }^{\circledR}$ y Boostrix ${ }^{\circledR}$ están comercialmente disponibles en Chile y recomendable para usarlas, cualquiera de ellas, especialmente en adolescentes después de 10 años de haber recibido la vacuna del programa nacional de inmunización en $2^{\circ}$ año básico (dT) y agregar refuerzos cada 10 años, para mantener una adecuada inmunidad para tétanos, difteria y coqueluche. 
Algunas de las estrategias propuestas para disminuir el impacto de esta enfermedad en la población susceptible a complicaciones son la denominada estrategia "capullo" y la inmunización materna, las cuales buscan proteger a neonatos y lactantes menores de posteriores exposiciones a la coqueluche. La primera consiste en la administración de la vacuna Tdap a puérperas antes del alta hospitalaria ${ }^{160}$ y a contactos intradomiciliarios mayores 12 años de edad dos a tres semanas antes del parto, ya que se ha demostrado que aproximadamente en $75 \%$ de los lactantes con coqueluche, la fuente de contagio corresponde a contactos en el hogar, identificándose a la madre como fuente infectante en $33 \%$ de los casos ${ }^{161,162}$. Adicionalmente se vacuna al personal de salud asistencial pediátrico en contacto con recién nacidos y lactantes.

En relación a la inmunización materna, la recomendación del Comité Asesor de Prácticas de Inmunización (Advisory Committee on Inmunization Practices-ACIP) es aplicar la vacuna Tdap a las mujeres embarazadas, preferiblemente después de las 20 semanas de gestación y así optimizar la transferencia de anticuerpos maternos ${ }^{163}$, ya que la protección pasiva por paso transplacentario de anticuerpos maternos ${ }^{164}$ es de bajos niveles y rápida disminución en el neonato, haciéndolo vulnerables a la infección grave ${ }^{165,166}$.

\section{Estudio colaborativo pediátrico sobre la CG}

Desde el año 2008 la organización The Collaborative Pediatric Critical Research Network (CPCRN) ${ }^{167}$ comenzó a desarrollar en E.U.A., un estudio de cohorte prospectivo y descriptivo el cual pretende reclutar 200 pacientes con diagnóstico de CG, teniendo como objetivo caracterizar el curso agudo de la enfermedad, evaluar las morbilidades asociadas y características demográficas de estos pacientes y a largo plazo las secuelas en el desarrollo y calidad de vida de los sobrevivientes. Actualmente, participan siete centros de E.U.A., los cuales han ingresado al estudio 96 pacientes en un período de dos años.

Asimismo, las cepas de $B$. pertussis aisladas serán enviadas a laboratorios de investigación para el estudio genético de las cepas causantes de CG, lo que permitirá distinguir entre las que causan enfermedad grave en lactantes de otras circulantes en la población, logrando una mayor comprensión de las probables fuentes de infección. De igual forma el aislamiento de estas cepas permitirá el desarrollo de futuras investigaciones sobre los mecanismos de virulencia y parámetros inmunes que participan en el control de la enfermedad. La información obtenida en este estudio permitirá guiar la toma de decisiones con respecto a la asignación de recursos para la prevención y tratamiento de la coqueluche, como también la generación de nuevas hipótesis sobre su fisiopatología y el desarrollo de nuevas estrategias terapéuticas para la $\mathrm{CG}^{168}$, con lo que se obtendría potencial beneficio para 500.000 niños que mueren anualmente por $\mathrm{CG}$ en el mundo ${ }^{169}$.

\section{Conclusión}

La CG es una enfermedad poco frecuente, pero altamente letal. Se presenta principalmente en niños bajo seis meses de edad y, en especial, en pacientes con vacunación ausente o incompleta. Los factores que desencadenan una evolución grave y la fisiopatología involucrada en este cuadro aún no están del todo dilucidadas. Por esto es fundamental tener un alto índice de sospecha epidemiológica y clínica, ya que una vez desencadenada la HTP, el tratamiento disponible habitualmente fracasa. Terapias de soporte avanzado no han resultado ser del todo exitosas; sin embargo, se deben considerar como opciones terapéuticas. En ocasiones las terapias de citorreducción han obtenidos resultados beneficiosos en estos pacientes.

Recientemente el Ministerio de Salud de nuestro país modificó el plan nacional de inmunizaciones, incorporando la vacunación con Tdap en primer año de enseñanza básica (6-7 años de edad). Asimismo, como la instauración de una estrategia de "capullo" a los padres y familiares de recién nacidos y también la vacunación del personal de salud pediátrico.

Estas políticas de salud están destinadas a prevenir y, por ende, reducir el impacto de esta patología en la población y así evitar el desarrollo de complicaciones, como la $\mathrm{CG}$, que coloquen en riesgo la vida del paciente.

\section{Resumen}

La coqueluche (tos ferina) es una enfermedad infectocontagiosa, que ha resurgido en los últimos años como problema de salud pública en nuestro país. La presentación clínica no ha cambiado, siendo los lactantes bajo un año el principal grupo de riesgo, evolucionando, en ocasiones hacia un cuadro altamente letal denominada coqueluche maligna o grave. En la presente revisión se discute su epidemiología, mecanismos de patogenicidad como también se describen los factores de riesgo, características clínicas de esta evolución y su fisiopatología. Se presenta la evidencia actual, utilidad de nuevos tratamientos y una propuesta de algoritmo terapéutico. 


\section{Referencias bibliográficas}

1.- Mortimer E, Cherry J. Pertussis (whooping cough). En: Krugman's Infectious Diseases of Children. 11th edition. Mosby, Inc 2004: 443-57.

2.- Circular B51 N²7,2011: "Vigilancia epidemiológica y medidas de control de coqueluche (tos ferina)", Ministerio de Salud, Chile.

3.- World Health Organization. Dept of vaccines and other biologicals. Pertussis surveillance: a global meeting: Geneva, 16-18 October 2000.

4.- Tan T, Trindade E, Skowronski D. Epidemiology of pertussis. Pediatr Infect Dis J 2005; 24 : S10-8.

5.- Aguas R, Goncalves G, Gomes M. Pertussis: increasing disease as a consequence of reducing transmission. Lancet Infect Dis 2006; 6: 112-7.

6.- Centers for Disease Control and Prevention (CDC). Pertussis-United States, 2001-2003. MMWR Morb Mortal Wkly Rep 2005; 23 (54): 1283-6.

7.- Donoso A, Wegner A, León J, Ramírez M, Carrasco J. Coqueluche en niños menores de 6 meses de vida. Rev Chil Pediatr 2001; 72: 334-9.

8.- Donoso A, Ramírez M, León J, Rojas G, Valverde C, Oberpaur W, et al. Coqueluche: una causa de HTP fatal. Rev Chilena Infectol 2002; 19: 226-30.

9.- Cofré J. Coqueluche en adultos y adolescentes. Rev Chilena Infectol 2003; 20: S52-58.

10.- Forsyth K. Pertussis, Still a formidable foe. Clin Infect Dis 2007; 45: 1487-91.

11.- Beiter A, Lewis K, Pineda E F, Cherry J D. Unrecognized maternal peripartum pertussis with subsequent fatal neonatalpertussis. Obstet Gynecol 1993; 82 (Suppl): 691-3.

12.- Centers for Disease Control and Prevention. Pertussis deaths; United States, 2000. MMWR Morb Mortal Wkly Rep 2002; 51: 616-8.

13.- Crowcroft NS, Andrews N, Rooney C, Brisson M, Miller E. Deaths from pertussis are underestimated in England. Arch Dis Child 2002; 86: 336-8

14.- Vitek CR, Pascual F B, Baughman AL, Murphy T V. Increase in deaths from pertussis among young infants in the United States in the 1990s. Pediatr Infect Dis J 2003; 22: 628-33.

15.- Falcon M, Rafael M, García C, Fergie J, Purcell K. Increasing infant pertussis hospitalization and mortality in South Texas, 1996 to 2006. Pediatr Infect Dis J 2010; 29: 265-7.

16.- World Health Organization. Challenges in global immunization and the global immunization vision and strategy 2006-2015. Wkly Epidemiol Rec 2006; 81: 190-5.

17.- Crowcroft N S, Stein C, Duclos P Birmingham M. How best to estimate the global burden of pertussis? Lancet Infect
Dis 2003; 3 : 413-8.

18.- CDC Especiales CDC: Tos ferina: lo que debe saber. Disponible en: http://www.cdc.gov/ spanish/especialesCDC/Tosferina. (Acceso 22 de diciembre de 2011)

19.- Ulloa-Gutiérrez R, Ávila-Aguero M. Pertussis in Latin America: current situation and future vaccination challenges. Expert Rev Vaccines 2008; 7: 1569-80

20.- World Health Organization. Disponible en: http://www.who.int/vaccines-documents/ GlobalSummary/GlobalSummary.pdf

21.- World Health Organization.Disponible en: http://www.amro.who.int/english/ad/fch/im/ Pertussis_NumberCases.pdf. Acceso 22 de diciembre de 2011.

22.- Laval E. Contribución a la historia de la coqueluche en Chile. Siglo XIX. Rev Chilena Infectol 2010; 27: 351-5.

23.- Sommers C. La mortalidad en Chile, durante los años 1892, 1893, 1894 y 1895. Rev Ch Hig 1896; 3: 374-95.

24.- Crónica. La coqueluche hace estragos. Rev Med Chile 1888-89; 17:525.

25.- Olea A. Ministerio de Salud de Chile. Departamento de Epidemiología, página web. Tos Ferina. El Vigía N² 24. Página 59 Disponible en: http://epi.minsal.cl/epi/html/ elvigia/Vigia24.pdf. (Acceso 23 de diciembre de 2011).

26.- Ministerio de Salud. Departamento de Epidemiología, pagina web. Informe de Coqueluche. Semana epidemiológica 1 a 49 (02 de enero al 10 de diciembre) Disponible en http:// epi.minsal.cl/epi/html/bolets/... Coqueluche/InformeCoqueluche.pdf. (Acceso el 24 de diciembre de 2011).

27.- Mattoo S, Cherry J. Molecular pathogenesis, epidemiology, and clinical manifestations of respiratory infections due to Bordetella pertussis and other Bordetella subspecies. Clin Microbiol Rev. 2005; 18: 326-82.

28.- Kerr J, Matthews R. Bordetella pertussis infection: pathogenesis, diagnosis, management, and the role of protective immunity. Eur J Clin Microbiol Infect Dis 2000; 19:77-88.

29.- Preston A. Bordetella pertussis: the intersection of genomics and pathobiology. Can Med Assoc J 2005; 173: 55-62.

30.- Uhl M, Miller J. Autophosphorylation and phosphotransfer in the Bordetella pertussis BvgAS signal transduction cascade. Proc Natl Acad Sci USA 1994; 91: 1163-7.

31.- Uhl M, Miller J. Central role of the BvgS receiver as a phosphorylated intermediate in a complex two-component phosphorelay. J Biol Chem 1996;271: 33176-80.

32.- Uhl M, Miller J. Integration of multiple domains in a two-component sensor protein: the Bordetella pertussis BvgAS phosphorelay. EMBO J 1996; 15: 1028-36.

33.- Stibitz S, Yang M S. Subcellular localization and immunological detection of proteins encoded by the vir locus of Bordetella pertussis. J Bacteriol 1991,173: 4288-96.

34.- Boucher P E, Stibitz S. Synergistic binding of RNA polymerase and BvgA phosphate to the pertussis toxin promoter of Bordetella pertussis. J Bacteriol 1995; 177: 6486-91.

35.- Heininger U. Recent progress in clinical and basic pertussis research. Eur J Pediatr 2001; 160: 203-13.

36.- Lacey B W. Antigenic modulation of Bordetella pertussis. J Hyg 1960; 58: 57-93.

37.- Friedman R L, Nordensson K, Wilson L, Akporiaye E T, Yocum D E. Uptake and intracellular survival of Bordetella pertussis in human macrophages. Infect Immun 1992; 60: 4578-85.

38.- Tozzi A, Celentano L, Ciofi degli Atti M L, Salmaso S. Diagnosis and management of pertussis. Can Med Assoc J 2005; 172: 509-15.

39.- Ishibashi Y, Nishikawa A. Bordetella pertussis infection of human respiratory epithelial cells up-regulates intercellular adhesion moleculeexpression: role of filamentous hemagglutinin and pertussis toxin. Microb Pathog 2002; 33: 115-25

40.- McEniery J, Delbridge R, Reith D. Infants pertussis deaths and the management of cardiovascular compromise. J Paediatr Child Health, 2004; 40: 230-2.

41.- Cherry J D, Grimprel E, Guiso N, Heininger U, Mertsola J. Defining pertussis epidemiology: clinical, microbiologic and serologic perspectives. Pediatr Infect Dis J 2005; 24: S25-S34.

42.- Flak T, Goldman W. Autotoxicity of nitric oxide in airway disease. Am J Respir Crit Care Med 1996; 154: S202-S6

43.- Munoz J J, Arai H, Bergman R K, Sadowski P L. Biological activities of crystalline pertussigen from Bordetella pertussis. Infect Immun 1981; 33: 820-6.

44.- Carbonetti N. Pertussis toxin and adenylate cyclase toxin: key virulence factors of Bordetella pertussis and cell biology tools. Future Microbiol 2010; 5: 455-69.

45.- Andreasen C, Carbonetti NH. Pertussis toxin inhibits early chemokine production to delay neutrophil recruitment in response to Bordetella pertussis respiratory tract infection in mice. Infect Immun 2008; 76: 5139-48.

46.- Carbonetti N H, Artamonova G V, Andreasen C, Dudley E, Mays R M, Worthington Z E. Suppression of serum antibody responses by pertussis toxin after respiratory tract colonization by Bordetella pertussis and identification of an immunodominant lipoprotein. Infect Immun 2004; 72: 3350-8.

47.- Kirimanjeswara G S, Agosto L M, Kennett M J, Bjornstad O N, Harvill E T. Pertussis toxin inhibits neutrophil recruitment to delay 
antibody-mediated clearance of Bordetella pertussis. J Clin Invest 2005; 115: 3594-601.

48.- Shumilla J A, Lacaille V, Hornell T M, Huang J, Narasimhan S, Relman DA, et al. Bordetella pertussis infection of primary human monocytes alters HLA-DR expression. Infect Immun 2004; 72: 1450-62.

49.- Martino A, Volpe E, Auricchio G, Colizzi V, Baldini P M. Influence of pertussis toxin on CD1a isoform expression in human dendritic cells. J Clin Immunol 2006; 26: 153-9.

50.- Aantaa R, Marjamaki A, Scheinin M. Molecular pharmacology of alpha 2-adrenoreceptor suptypes. Ann Med 1995; 27: 439-49.

51.- Huff R M. Signal transduction pathways modulated by the D2 subfamily of dopamine receptors. Cell Signal 1996; 8: 453-9.

52.- Higgins S C, Lavelle E C, McCann C, Keogh B, McNeela E, Byrne P, et al. Toll-like receptor 4-mediated innate IL-10 activates antigen-specific regulatory $T$ cells and confers resistance to Bordetella pertussis by inhibiting inflammatory pathology. J Immunol 2003; 171 3119-27.

53.- Moci F R. Bordetella pertussis and vaccination: the persistence of genetically monomorphic pathogen. Infect Genet Evol 2010; 10: 36-49.

54.- Mooi F R, van Oirschot H, Heuvelman K, van der Heide H G, Gaastra W, Willems R J. Polymorphism in the Bordetella pertussis virulence factors P.69/pertactin and pertussis toxin in The Netherlands: temporal trends and evidence for vaccine-driven evolution. Infect Immun 1998; 66: 670-5.

55.- Kallonen T, He Q. Bordetella pertussis strain variation and evolution postvaccination. Expert Rev Vaccines 2009; 8: 863-75.

56.- Hozbor D, Mooi F, Flores D, Weltman G, Bottero D, Fossati S, et al. Pertussis epidemiology in Argentina: trends over 20042007. J Infect 2009; 59: 225-31.

57.- Mooi F R, van Loo I H M, van Gent M, He Q, Heuvelman C J, Bart M, et al. Bordetella pertussis strains with increased toxin production associated with pertussis resurgence. Emerg Infect Dis 2009; 15: 1206-13.

58.- Cherry J D, Brunnell P A, Golden G S, Karzon D T. Report of the task forcé on pertussis and pertussis immunization. Pediatrics 1988; 81: 939-84

59.- Wood N, McIntyre P. Pertussis: review of epidemiology, diagnosis, management and prevention. Paediatr Respir Rev 2008; 9: 201-11.

60.- Muñoz F. Pertussis in infants, children, and adolescents: diagnosis, treatment, and prevention. Semin Pediatr Infect Dis 2006; 17: 14-9.

61.- von Konig C H, Halperin S, Riffelmann M, Guiso N. Pertussis of adults and infants. Lancet Infect Dis 2002; 2: 744-50.

62.- Heininger U, Klich K, Stehr K, Cherry J
D. Clinical findings in Bordetella pertussis infections: results of a prospective multicenter surveillance study. Pediatrics 1997; 100: E10.

63.- Romanus V, Jonsell R, Bergquist S O. Pertussis in Sweden after the cessation of general immunization in 1979. Pediatr Infect Dis J 1987; 6: 364-71.

64.- Effect of a low pertussis vaccination uptake on a large community. Report from the Swansea Research Unit of The Royal College of General Practitioners. Br Med J (Clin Res Ed) 1981; 282: 23-6.

65.- Martínez M, Rochant I, Corbelli R, Tissères P, Rimensberger P. Early blood exchange transfusion in malignant pertussis: A case report. Pediatr Crit Care Med 2011; 12: 1-3.

66.- Berthomieu L, Boumahni B, Jamal Bey K, Peslagesb P, Rayetb I, Teyssierb G. La coqueluche maligne: à propos de 3 observations. Arch Pèdiatr 2010; 17: 144-8.

67.- Namachivayam P, Shimizu K, Butt W. Pertussis: severe clinical presentation in pediatric intensive care and its relation to outcome. Pediatr Crit Care Med 2007; 8: 207-11.

68.- Stojanov S, Liese J, Belohradsky B. Hospitalization and complications in children under 2 years of age with Bordetella pertussis infection. Infection 2000; 28: 106-10.

69.- Heininger U, Stehr K, Cherry J. Serious pertussis overlooked in infants. Eur J Pediatr 1992; 151: 342-3.

70.- Goulin G, Kaya K, Bradley J. Severe pulmonary hypertension associated with shock and death in infants infected with Bordetella pertussis. Crit Care Med 1993; 21: 1791-4.

71.- Mikelova L, Halperin S, Scheifele D, Smith B, Ford-Jones E, Vaudry W et al. Predictors of death in infants hospitalized with pertussis: a case-control study of 16 pertussis deaths in Canada. J Pediatr 2003; 143: 576-81.

72.- Crowcroft NS, Booy R, Harrison T, Spicer L, Britto J, Mok Q et al. Severe and unrecognised: pertussis in UK infants. Arch Dis Child 2003; 88: 802-6.

73.- Briand V, Bonmarin I, Lévy Bruhl D. Study of the risk factors for severe childhood pertussis based on hospital surveillance data. Vaccine 2007; 25: 7224-32.

74.- Surridge J, Segedin E R, Grant CC. Pertussis requiring intensive care. Arch Dis Child 2007; 92: 970-5.

75.- Pierce C, Klein N, Peters M. Is leukocytosis a predictor of mortality in severe pertussis infection? Intensive Care Med 2000; 26: 1512-4.

76.- Sawal M, Cohen M, Irazuzta J, Kumar R, Kirton C, Brundler M A. Fulminant pertussis: A multi-center study with insights into the clinicpathological mechanism. Pediatr Pulmonol 2009; 44: 970-80.

77.- Rowlands H, Goldman A, Harrington K,
Karimova A, Brierley J, Cross N. et al. Impact of rapid leukodepletion on the outcome of severe clinical pertussis in young infants. Pediatrics 2010; 126: e816-e27.

78.- Sreenan CD, Osiovich H. Neonatal pertussis requiring extracorporeal membrane oxygenation. Pediatr Surg Int 2001; 17: 201-3.

79.- Cruces P, González M, Maldonado B, Cruces K. Coqueluche grave con hipertensión pulmonar tratado con exanguineotransfusión. Rev Chil Pediatr 2005; 76: 513-7.

80.- Paddock C, Sanden G, Cherry J, Gal A, Langston C, Tatti K, et al. Pathology and pathogenesis of fatal Bordetella pertussis infection in infants. Clin Infect Dis 2008:; 47: 328-38.

81.- Williams G D, Numa A, Sokol J, Tobias V, Duffy B J. ECLS in pertussis: does it have a role? Intensive Care Med 1998; 24: 1089-92.

82.- Casano P, Odena MP, Cambra F, Martin J, Palomeque A. Bordetella pertussis infection causing pulmonary hypertension. Arch Dis Child 2002; 86: 453.

83.- De Berry B, Lynch J, Chung D, Zwischenberger J. Pertussis with severe pulmonary hypertension and leukocytosis treated with extracorporeal membrane oxygenation. Pediatr Surg Int 2005; 21 692-4

84.- Jiang B, Morimoto S, Fukuo K, Hirotani A, Tamatani M, Nakahashi T, et al. Parathyroid hormone-related protein inhibits endothelin-1. Hypertension 1996; 27: 360-3.

85.- Halasa N, Barr F, Johnson J, Edwards K. Fatal pulmonary hypertension associated with pertussis in infants: does extracorporeal membrane oxygenation have a role? Pediatrics 2003; 112: 1274-8.

86.- Donoso A, Cruces P, Camacho J, León J, Kong J. Exchange transfusion to reverse severe pertussis-induced cardiogenic shock. Pediatr Infect Dis J 2006; 25: 846-8.

87.- Romano M J, Weber M D, Weisse M E, Siu B. Pertussis pneumonia, hypoxemia, hyperleukocytosis, and pulmonary hypertension: improvement in oxygenation after a double volume exchange transfusion. Pediatrics 2004; 114: e264-6.

88.- Ryan M, McCarthy L, Rappuoli R, Mahon B P, Mills KH. Pertussis toxin potentiates Th1 and Th2 responses to co-injected antigen: Adjuvant action is associated with enhanced regulatory cytokine production and expression of the costimulatory molecules B7-1, B7-2 and CD28. Int Immunol 1998; 10: 651-62.

89.- Fujimoto C, Yu C R, Shi G, Vistica B P, Wawrousek E F, Klinman D M, et al. Pertussis toxin is superior to TLR ligands in enhancing pathogenic autoimmunity, targeted at a neoself antigen, by triggering robust expansion of Th1 cells and their cytokine production. J Immunol 2006; 177: 6896-903. 
90.- Cassan C, Piaggio E, Zappulla J P, Mars L T, Couturier N, Bucciarelli F, et al. Pertussis toxin reduces the number of splenic Foxp3+ regulatory T cells. J Immunol 2006; 177: 1552-60.

91.- Tonon S, Badran B, Benghiat F S, Goriely S, Flamand V, Willard-Gallo K, et al. Pertussis toxin activates adult and neonatal naïve lymphocytes. Eur J Immunol 2006; 36: 1794-804.

92.- Jutila M, Rott L, Berg E, Butcher E. Function and regulation of the neutrophil MEL-14 antigen in vivo. Comparison with LFA-1 and MAC-1. J Immunol 1989; 143: 3318-24

93.- Lewinsohn D, Bargatze R, Butcher E. Leukocyte-endothelial cell mechanism shared by neutrophils, lymphocytes and other leukocytes. J Immunol 1987; 138: 4313-21.

94.- Smith C, Kishimoto T, Abbas O, Huges B, Rothlein R, McIntire L, et al. Chemotactic factors regulate lectin adhesion molecule 1 (LECAM-1) development neutrophil adhesion to cytokine-stimulated endothelial cells in vitro. J Clin Invest 1991; 87: 609-18.

95.- Felmet K A, Hall M W, Clark R S B, Jaffe R, Carcillo J A. Prolonged lymphopenia, lymphoid depletion, and hypoprolactinaemia in children with nocosomial sepsis and multiple organ failure. J Immunol 2005; 174: 3765-72.

96.- Hotchkiss R S, Swanson P E, Freeman B D, Tinsley K W, Cobb J P, Matuschak G M, et al. Apoptotic cell death in patients with sepsis, shock, and multiple organ dysfunction. Crit Care Med 1999; 27: 1230-51.

97.- Forse R A. Biology of heterotrimeric G protein signaling: Signal transduction in critical care medicine. Crit Care Med 2000; 28 (Suppl): N53-9.

98.- Sodhi A, Montaner S, Gutkind J S. Viral hijacking of G-protein-coupled-receptor signaling networks. Nat Rev Mol Cell Biol 2004; 5: 998-1012.

99.- Bem R A, Bos A P, Matute-Bello G, van Tuyl $M$, van Woensel JBM. Lung epithelial cell apoptosis during acute lung injury in infancy. Pediatr Crit Care Med 2007; 8: 132-7.

100.-Mallory F B, Hornor A A. Pertussis: the histological lesion in the respiratory tract. J Med Res 1912; 27: 115-23.

101.-Lapin J H. Whooping cough. Springfield I L: Charles C. Thomas, 1943.

102.-Smith L W. The pathological anatomy of pertussis with especial refence to pneumonia caused by the pertussis bacillus. Arch Pathol Lab Med 1927; 4: 732-42.

103.-Grzeszczak M, Churchwell K, Edwards K, Pietsch J. Leukopheresis therapy for severe infantile pertussis with myocardial and pulmonary failure. Pediatr Crit Care Med 2006; 7: 580-2.

104.-Sugimoto M, Nakanishi Y, Otokawa M, Uchida N, Yasuda T, Sato H, et al. Effect of Bordetella pertussis leucocytosis (lymphocytosis)- promoting factor (LPF) on the physical lymphoepithelial-cell association studied with the use of an in vitro model of mouse thymus. J Immunol 1983; 130: 2767-74.

105.-Smith C, Vyas H. Early infantile pertussis: increasingly prevalent and potentially fatal. Eur J Pediatr 2000; 59: 898-900.

106.-Hoppe J E. State of art in antibacterial susceptibility of Bordetella pertussis and antibiotic treatment of pertussis. Infection 1998; 26: $242-6$

107.-Kurzynski T A, Boehm D M, Rott-Petri J A, Schell R F, Allison P E. Antimicrobial susceptibilities of Bordetella species isolated in a Multicenter Pertussis Surveillance Project. Antimicrob Agents Chemother 1988; 32: 137-40.

108.-Bass J W. Erythromycin for treatment and prevention of pertussis. Pediatr Infect Dis J 1986; 5: 154-7.

109.-Centers for Disease Control. Erythromycinresistant Bordetella pertussis, Yuma County, Arizona, May-October 1994. MMWR Morb Mortal Wkly Rep 43: 807-10.

110.-Lewis K, Saubolle M A, Tenover F C, Rudinsky M F, Barbour S D, Cherry J D. Pertussis caused by an erythromycin-resistant strain of Bordetella pertussis. Pediatr Infect Dis J 1995; 14: 388-91.

111.-Korgenski E K, Daly J A. Surveillance and detection of erythromycin resistance in Bordetella pertussis isolates recovered from a pediatric population in the Intermountain West region of the United States. J Clin Microbiol 1997; 35: 2989-91.

112.- Yao S-M, Liaw G-J, Chen Y-Y, Yen M-H, Chen Y- H, Mu J-J, et al. Antimicrobial susceptibility testing of Bordetella pertussis in Taiwan prompted by a case of pertussis in a paediatric patient. J Med Microbiol 57: 1577-80.

113.-Fry N, Duncan J, Vaghji L, George R, Harrison T. Antimicrobial susceptibility testing of historical and recent clinical isolates of Bordetella pertuss in the United Kingdom using the Etest method. Eur J Clin Microbiol Infect Dis 2010; 29: 1183-5.

114.-Halpering S A, Bortolussi R, Langley J M, Miller B, Eastwood B J. Seven day of erythromycin estolate is as effective as fourteen days for treatment of Bordetella pertussis infections. Pediatrics 1997; 100: 65-70.

115.-Tozzi A E, Rava L, Ciofi degli Atti M L, Salmaso S. Clinical presentation of pertussis in unvaccinated and vaccinated children in the first six years of life. Pediatrics 2003; 112: 1069-75.

116.-Bergquist S, Bernander S, Dahnsjo H, Sundelof B. Erythromycin in the treatment of pertussis: a study of bacteriologic and clinical effects. Pediatr Infect Dis J 1987; 6: 458-61.

117.-Hoppe J E. The Erythromycin Study Group. Comparison of erythromycin estolate and erythromycin ethylsuccinate for treatment of pertussis. Pediatr Infect Dis J 1992; 11: 189-93.

118.-Kerr J R, Preston N W. Current pharmacotherapy of pertussis. Expert Opin Pharmacother 2001; 2: 1275-82.

119.-Steinberg J M, Srugo I. Reoccurrence of culturepositive pertussis in an infant initially treated with azithromycin and steroids. Arch Pediatr Adolesc Med 2002; 156: 1057-8.

120.-von König C H, Schmitt H J, Bogaerts H, et al. Factors influencing the spread of pertussis in households. Eur J Pediatr 1998; 157: 391-4.

121.-Committe on Infectious Diseases, American Academy of Pediatrics (2006) Pertussis. In: Pickering L K, Baker C J, Long S S, McMillan J A (eds) Red book: Report of the Committee on Infectious Diseases, 27th edn. Elk Grove Village, IL, pp 498-520.

122.-Morrison W. Infantile hypertrophic pyloric stenosis in infants treated with azithromicyn. Pediatr Infect Dis J 2007; 26: 186-8.

123.-Cofré J. Quimioprofilaxis en coqueluche: ¿Sacar agua a canastos? Rev Chilena Infectol 2006; 23: 60-8.

124.-Altunaiji S, Kukuruzovic R, Curtis N, Massie J. Antibiotics for whooping cough (pertussis). Cochrane Database Syst Rev 2005; 25 (1). Acceso 17 de noviembre de 2011.

125.-NHMRC-National Health and Medical Research Council. Pertussis en: The Australian Immunisation Handbook 8th ed.2003. http:// www.nhmrc.gov.au/publications/subjects/ communicable.htm. (Acceso 17 de noviembre de 2011).

126.-Dodhia H, Crowcroft NS, Bramley JC, Miller E. UK guidelines for use of erythromycin chemoprophylaxis in persons exposed to pertussis. J Public Health Med 2002; 24: 200-6.

127.-National Consensus Conference on Pertussis. Canada Communicable Disease Report. 2003. Volume 2953. http://www.hc-sc.gc.ca/pphbdgspsp. (Acceso 17 de noviembre de 2011).

128.-Vigilancia epidemiológica y medidas de control de coqueluche (tos ferina). Disponible en: http:// epi.minsal.cl/epi/html/normas/circul/CircularCoqueluche.pdf. (Acceso 17 de noviembre de 2011).

129.-Donoso A, León J, Ramírez M, Rojas G, Oberpaur B. Pertussis and fatal pulmonary hypertension: a discouraged entity. Scand J Infect Dis 2005; 37: 145-8.

130.-Egan J, Clarke A, Williams S, Cole AD, Ayer J, Jacobe S, et al. Levosimendan for low cardiac output: a pediatric experience. J Intensive Care Med 2006; 21: 183-7.

131.-Verrijk R, De Wildt D J, Van Rooij H H, Wemer J, Porsius A J. Cardiovascular responses to milrinone in pertussis toxin-pretreated pithed rats. Eur J Pharmacol 1990; 191: 197-204. 
132.-Hollenberg S. Vasoactive drugs in circulatory shock. Am J Respir Crit Care Med 2011; 183 : 847-55.

133.-von Rosenstiel I, Plotz F. ECLS in pertussis: does it have a role? Intensive Care Med 1999; 25: 1341-2.

134.-Pooboni S, Roberts N, Westrope C, Jenkins D R, Killer H, Pandya H C, et al. Extracorporeal life support in pertussis. Pediatr Pulmonol 2003; 36: 310-5.

135.-Heiss L N, Lancaster J R Jr, Corbett J A, Goldman W E. Epitelial autotoxicity of nitric oxide: role in the respiratory cytopathology of pertussis. Proc Natl Acad Sci USA 1994; 91 : 269-70.

136.-Heiss L N, Moser S A, Unanue E R, Goldman W E. Interleukin-1 is linked to the respiratory epithelial cytopathology of pertussis. Infect Immun. 1993; 61: 3123-8.

137.-Hibbs J Jr, Taintor R, Vavrin Z, Granger D, Drapier, J, Amber I, et al. In nitric oxide from L-arginine: A bioregulatory system. Moncada S \& Higgs E A, eds. (Elsevier, Amsterdam), pp. 189-223.

138.-Petros A, Pierce C. The management of pulmonary hypertension. Pediatr Anaesth 2006; 16: 816-21.

139.-Soares S, Rocha G, Pissarra S, Carriço A, Azevedo I, Sobrinho Simões J. Pertussis with severe pulmonary hypertension in a newborn with good outcome-case report. Rev Port Pneumol 2008; XIV: 687-92.

140.-Fraisse A, Wessel D. Acute pulmonary hypertension in infants and children: cGMPrelated drugs. Pediatr Crit Care Med 2010; 11 (suppl): s37-s40.

141.-Farrow K, Fliman P, Steinhorn R H. The diseases treated with ECMO: focus on PPHN. Semin Perinatol 2005; 29: 8-14.

142.-Inwald D, Brown F, Gensini F , Malone M, Goldman A. Open lung biopsy in neonatal and paediatric patients referred for extracorporeal membrane oxygenation (ECMO). Thorax 2004; 59: 328-33.

143.-Bunin N J, Kunke L K, Callihan T R. Cytoreductive procedures in the early management in cases of leukemia and hyperleukocytosis in children. Med Pediatr Oncol 1987; 15: 232-5.

144.-Ulloa-Gutiérrez R, Boza R, Carvajal-Riggioni D, Baltodano A. Pertussis: should we improve intensive care management or vaccination strategies? Expert Rev Vaccines 2011; 10: 49-53.
145.-Ichimaru T, Ohara Y, Hojo M, Miyazaki S, Harano K, Totoki T. Treatment of severe pertussis by administration of specific gamma globulin with high titers anti-toxin antibody. Acta Paediatr 1993; 82: 1076-8.

146.-Granstrom M, Olinder-Nielsen A M, Holmblad P, Mark A, Hanngren K. Specific immunoglobulin for treatment of whooping cough. Lancet 1991; 338: 1230-3.

147.-Bruss J, Malley R, Halperin S, et al. Treatment of severe pertussis: a study of the safety and pharmacology of intravenous pertussis immunoglobulin. Pediatr Infect Dis J 1999; 18: 505- 11.

148.-Bruss J, Siber G. Protective effects of pertussis immunoglobulin (P-IGIV) in the aerosol challenge model. Clin Diagn Lab Immunol 1999; 464-70.

149.-Halperin S, Vaudry W, Boucher F, Mackintosh K, Waggener T, Smith B. Is pertussis immune globulin efficacious for the treatment of hospitalized infants with pertussis? No answer yet. Pediatr Infect Dis J 2007; 26: 79-81.

150.-Perret C. Vacuna anti-pertussis para adolescentes y adultos. Rev Chilena Infectol 2006; 23: 257-60.

151.-Van der Wielen M, Van Damme P, Van ERC K, Schleger-Haueter S, Siegrist C A. Seroprevalence of Bordetella pertussis antibodies in Flandes (Belgium). Vaccine 2003; 21: 2412-7.

152.-Miller E, Gay N J. Epidemiological determinants if pertussis. Dev Biol Stand 1997; 89: 15-23.

153.-Wirsing von Köning C H, Postels-Multani S, Bock H L, Schimitt H J. Pertussis in adults: frecuency of transmission after household exposure. Lancet 1995; 36: 1326-9.

154.-Halperin S A. The control of pertussis-2007 and beyond. N Engl J Med 2007; 356: 110-13.

155.-Wendelboe A, Van Rie A, Salmaso S, Englund J. Duration of immunity against pertussis after natural infection of vaccination. Pediatr Infect Dis J 2005; 24: S58-S61.

156.-Perret C, Viviani T, Peña A, Abarca K, Ferres M. Fuente de infección de Bordetella pertussis en lactantes hospitalizados por coqueluche. Rev Med Chile 2011; 139: 448-54.

157.-C.D.C. Preventing Tetanus, Diphtheria, and Pertussis among adolescents: Use of Tetanus Toxoid, Reduced Diphtheria Toxoid and Acellular Pertussis Vaccine MMWR Morb
Mortal Wkly Rep 2006; 55: 1-34.

158.-ADACEL ${ }^{\text {TM: }}$ Tdap Vaccine: Tetanus Toxoid, Reduced Diphtheria Toxoid and Acellular Pertussis Vaccine Absorbed. VRBPAC Briefing: Document 2005 Sanofi Pasteur Limited. Pag $1-102$.

159.-FDA Approval Boostrix $® 2009$ MMWR Morb Mortal Wkly Rep 58 (14); 374-5.

160.-Libster R, Edwards K. How can we best prevent pertussis in infants? Clin Infect Dis 2012; 54: 85-7.

161.-Bisgard K, Pascual F, Ehresmann K, et al. Infant pertussis: who was the source? Pediatr Infect Dis J 2004; 23: 985-9.

162.-Castagnini L A, Muñoz F M. Clinical characteristics and outcomes of neonatal pertussis: a comparative study. J Pediatr 2010; 156: 498-500

163.-Centers for Disease Control and Prevention. Updated Recommendations for Use of Tetanus Toxoid, Reduced Diphtheria Toxoid and Acellular Pertussis Vaccine (Tdap) in Pregnant Women and Persons Who Have or Anticipate Having Close Contact with an Infant Aged $<12$ Months-Advisory Committee on Immunization Practices (ACIP). MMWR Morb Mortal Wkly Rep 2011; 60: 1424-6.

164.-J W, Zacher L L. Do newborns have passive immunity to pertussis? Pediatr Infect Dis J 1989; 8: 352-3.

165.-Forsyth K, Tan T, von Konig C H, Caro J J, Plotkin S. Potential strategies to reduce the burden of pertussis. Pediatr Infect Dis J 2005; 24: S69-74.

166.-Healy C M, Muñoz F M, Rench M A, Halasa N B, Edwards K M, Baker C J. Prevalence of pertussis antibodies in maternal delivery cord and infant serum. J Infect Dis 2004; 190: 335-40.

167.-Burr J, Jenkins T, Harrison R, Meert K, Anand K, Berger J. The Collaborative Pediatric Critical Research Network Critical Pertussis Study: Collaborative research in pediatric care medicine. Pediatr Crit Care Med 2011: 12; 387-92.

168.-Jouvet P, Emeriaud G. Critical pertussis: an example of pediatric disease that necessitates a large collaborative network. Pediatr Crit Care Med 2011; 12: 467-8.

169.-Long S S. Pertussis (Bordetella pertussis and Bordetella parapertussis). In: Nelson Textbook of Pediatrics. Eighteenth Edition. Kliegman R, Nelson WE (Eds). Philadelphia, Saunders, 2007, pp $1178-82$. 